\title{
A narrative review of tumor-associated macrophages in lung cancer: regulation of macrophage polarization and therapeutic implications
}

\author{
Sahar Sadat Sedighzadeh ${ }^{1,2}$, Amin Pastaki Khoshbin ${ }^{2,3}$, Sepideh Razi ${ }^{2,4}$, Mahsa Keshavarz-Fathi ${ }^{2,3}$, \\ Nima Rezaei ${ }^{5,6,7}$
}

${ }^{1}$ Department of Biological Sciences, Faculty of Science, Shahid Chamran University of Ahvaz, Ahvaz, Iran; ${ }^{2}$ Cancer Immunology Project (CIP), Universal Scientific Education and Research Network (USERN), Tehran, Iran; ${ }^{3}$ School of Medicine, Tehran University of Medical Sciences, Tehran, Iran; ${ }^{4}$ School of Medicine, Iran University of Medical Sciences, Tehran, Iran; ${ }^{5}$ Research Center for Immunodeficiencies, Children's Medical Center, Tehran University of Medical Sciences, Tehran, Iran; ${ }^{6}$ Department of Immunology, School of Medicine, Tehran University of Medical Sciences, Tehran, Iran; ${ }^{7}$ Cancer Immunology Project (CIP), Universal Scientific Education and Research Network (USERN), Sheffield, UK

Contributions: (I) Conception and design: SS Sedighzadeh, AP Khoshbin, S Razi, M Keshavarz-Fathi, N Rezaei; (II) Administrative support: S Razi, M Keshavarz-Fathi, N Rezaei; (III) Provision of study materials or patients: None; (IV) Collection and assembly of data: SS Sedighzadeh; (V) Data analysis and interpretation: None; (VI) Manuscript writing: All authors; (VII) Final approval of manuscript: All authors.

Correspondence to: Nima Rezaei, MD, PhD. Research Center for Immunodeficiencies, Children's Medical Center, Dr Qarib St, Keshavarz Blvd, 14194

Tehran, Iran. Email: rezaei_nima@tums.ac.ir; rezaei_nima@yahoo.com.

\begin{abstract}
Lung cancer is the deadliest malignancy worldwide. An inflammatory microenvironment is a key factor contributing to lung tumor progression. Tumor-Associated Macrophages (TAMs) are prominent components of the cancer immune microenvironment with diverse supportive and inhibitory effects on growth, progression, and metastasis of lung tumors. Two main macrophage phenotypes with different functions have been identified. They include inflammatory or classically activated (M1) and antiinflammatory or alternatively activated (M2) macrophages. The contrasting functions of TAMs in relation to lung neoplasm progression stem from the presence of TAMs with varying tumor-promoting or anti-tumor activities. This wide spectrum of functions is governed by a network of cytokines and chemokines, cell-cell interactions, and signaling pathways. TAMs are promising therapeutic targets for non-small cell lung cancer (NSCLC) treatment. There are several strategies for TAM targeting and utilizing them for therapeutic purposes including limiting monocyte recruitment and localization through various pathways such as CCL2CCR2, CSF1-CSF1R, and CXCL12-CXCR4, targeting the activation of TAMs, genetic and epigenetic reprogramming of TAMs to antitumor phenotype, and utilizing TAMs as the carrier for anti-cancer drugs. In this review, we will outline the role of macrophages in the lung cancer initiation and progression, pathways regulating their function in lung cancer microenvironment as well as the role of these immune cells in the development of future therapeutic strategies.
\end{abstract}

Keywords: Macrophages; lung neoplasms; macrophage activation; immunotherapy

Submitted Dec 05, 2020. Accepted for publication Feb 26, 2021.

doi: $10.21037 /$ tlcr-20-1241

View this article at: http://dx.doi.org/10.21037/tlcr-20-1241

\section{Introduction}

Lung cancer is the primary and the secondary cause of cancer-related death for men and women worldwide, respectively (1). It is categorized into two main types, including small cell lung cancer (SCLC) and non-small cell lung cancer (NSCLC), the latter type accounts for about $80-85 \%$ of all cases of lung cancer (2). More than $55 \%$ of all patients with NSCLC are diagnosed at advanced 
stages of the disease (3). Available treatment options for NSCLC are surgical resection of the primary tumor or metastatic lesion, radiation therapy, and systemic therapies. Conventional chemotherapies, drugs targeting commonly mutated pathways in lung cancer, and immune checkpoint inhibitors are our current armamentarium of systemic therapies for NSCLC (4). Despite promising advances in the systemic management of lung cancer, 5 -year survival rates for localized, regional, and metastatic lung cancer are $57.4 \%, 30.8 \%$, and $5.2 \%$, respectively (5). Cancer progression during or after treatment with systemic therapies are the major cause of death in NSCLC. Hence, resistance to systemic therapies is considered a serious obstacle in the therapy of NSCLC. Therefore, finding new therapeutic strategies can improve the prognosis of patients with NSCLC (6).

The functional association between inflammation and cancer is extensively investigated. The link between inflammation and cancer dates back to the $19^{\text {th }}$ century when Rudolf Virchow for the first time proved the presence of leukocytes within tumors (7). Subsequently, it has been revealed that cancer-related inflammation can impact all stages of tumorigenesis, including initiation, promotion, angiogenesis, and metastasis of established tumors $(8,9)$. Likewise, lung cancer is one of the cancers associated with inflammation. Immune responses mediate the effect of environmental exposures on lung cancer initiation, control the invasion and metastasis of lung tumor, and are therapeutic targets for lung cancer treatment (10).

The tumor microenvironment is composed of tumor cells, innate and adaptive immune cells, fibroblasts, vascular and lymphatic endothelial cells, extracellular matrix, growth factors, cytokines, chemokines, hormones, and proteases among others $(6,11)$. Interplays between tumor cells and immune cells in the tumor microenvironment, e.g., through production and secretion of tumor-regulating cytokines by immune cells, control tumor cell survival, and metastasis (12). Innate immune cells, particularly natural killer cells (NK cells) and macrophages exert a great impact on cancer and play a pivotal pattern in the regulation of tumor progression and inhibition (13).

Macrophages within the tumor microenvironment are referred to as tumor-associated macrophages (TAMs). In the NSCLC microenvironment, TAMs constitute the predominant cellular component. They not only act as immunosuppressive cells enabling immune evasion of NSCLC but also directly contribute to cancer cell proliferation, survival, invasion, and metastasis (14). Two main macrophage phenotypes with different functions have been identified. They include inflammatory or classically activated (M1) and anti-inflammatory or alternatively activated (M2) macrophages (15). M1 macrophages usually arise in the setting of inflammatory surroundings that are usually induced by type $1 \mathrm{~T}$ helper (Th1) cytokines such as interferon gamma (IFN- $\gamma$ ), Toll-Like Receptor (TLR) agonists like lipopolysaccharide (LPS), and GranulocyteMonocyte Colony-Stimulating Factor (GM-CSF) (16,17). This type of macrophage secretes higher levels of proinflammatory cytokines such as tumor necrosis factor-alpha (TNF- $\alpha$ ), interleukin (IL)- $1 \alpha / \beta$, IL-6, IL-12, and IL-23, lower levels of IL-10 than M2 macrophages and produces inducible nitric oxide synthase (iNOS). The phosphorylated form of STAT1 as a transcription factor, CD80, CD86, and CD64 are some common M1 biomarkers (16,18-20). M1 macrophages regulate a potent immune response against pro-inflammatory situations and microbial activity. M2 macrophages are found in environments associated with type $2 \mathrm{~T}$ helper (Th2) cytokines. M2 phenotype consists of four well-defined subtypes including M2a induced by IL-4 and IL-13; M2b induced by immune complexes and IL-1 receptor agonists; M2c induced by IL-10, Transforming Growth Factor-Beta (TGF- $\beta$ ), and glucocorticoids; and M2d induced by IL-6, Leukemia Inhibitory Factor (LIF) and adenosine. Although M2 macrophage subtypes have anti-inflammatory and immunoregulatory roles in common, they also exhibit different functions. For example, M2a subtype is involved in tissue fibrosis, $\mathrm{M} 2 \mathrm{~b}$ subtype contributes to tumor progression, M2c subtype is responsible for tissue remodeling, and M2d subtype promotes angiogenesis (21). Some common markers for M2 macrophages are arginase, CD206, CD204, and CD163. M2 macrophages are well-adapted to inflammatory response inhibitors and tumor progression (17,21) (Figure 1).

Density, phenotype, and microanatomical localization of macrophages are considered efficient biological parameters for patient survival prediction (22). The increasing number of evidence indicates that M2 TAM density has a strong correlation with advanced tumor progression (23-25). Since M2 TAMs act as pro-tumoral macrophages and contribute to lung cancer progression (26), they are beginning to be assessed as promising therapeutic targets for lung cancer treatment. Strategies for TAM targeting and utilizing them for therapeutic purposes include limiting monocyte recruitment and localization, targeting the activation of TAMs, reprogramming TAMs to antitumor phenotype, and 


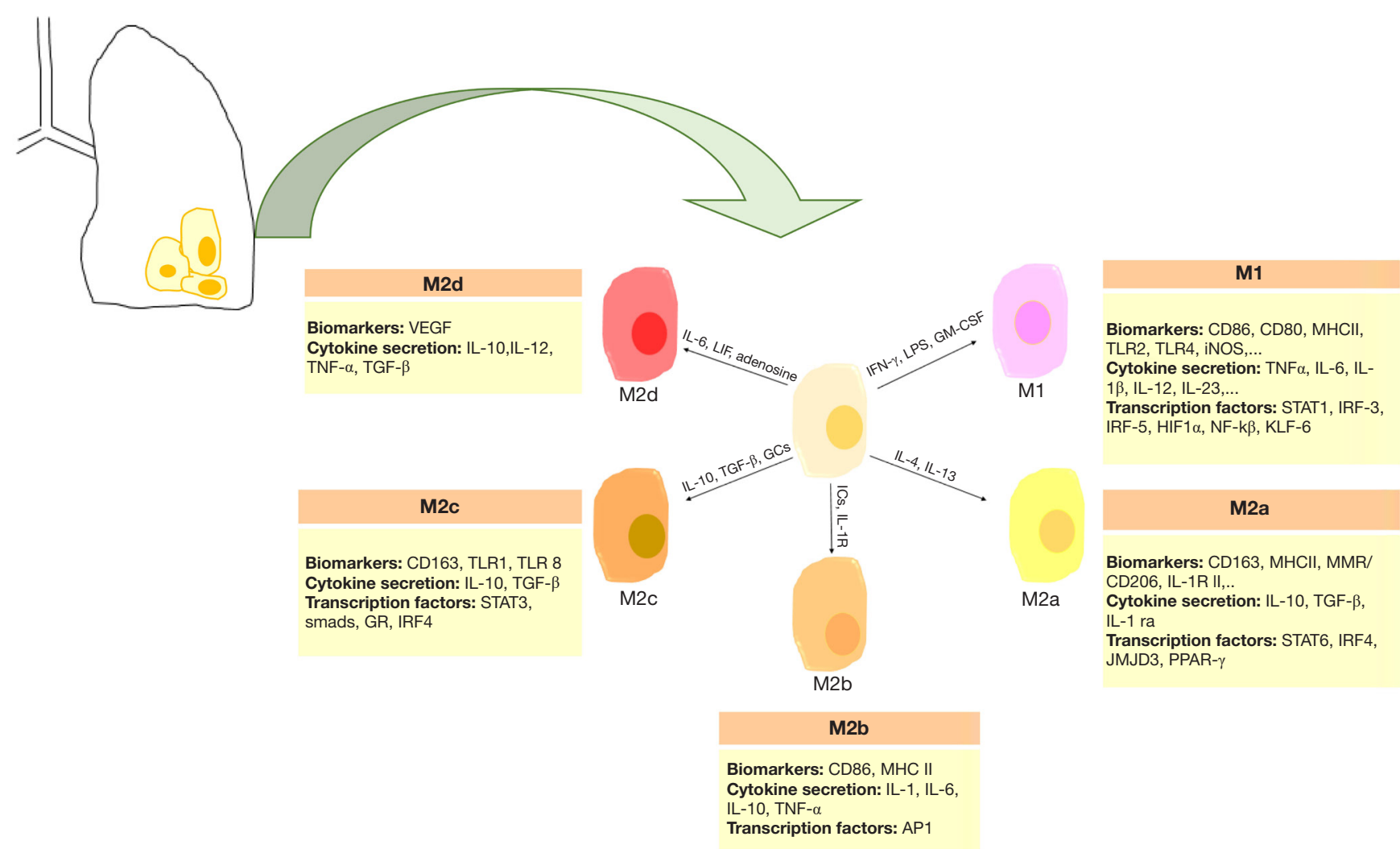

Figure 1 Pulmonary macrophage polarization. Various induction signals polarize pulmonary macrophages into M1 or M2 phenotype. AP1, activator protein 1; GM-CSF, granulocyte-macrophage colony-stimulating factor; GR, glucocorticoid receptor; HIF1 $\alpha$, hypoxia-inducible factor alpha; ICs, immune complexes; IL, interleukin; IL-1R, interleukin-1 receptor; IL-1Ra, interleukin-1 receptor antagonist; iNOS, inducible nitric oxide synthase; IRF, interferon regulatory factor; JMJD3, Jumonji domain containing 3; KLF, kruppel-like factor; LIF, leukemia inhibitory factor; LPS, lipopolysaccharide; MHC, major histocompatibility complex; MMR, macrophage mannose receptor; NF$\kappa \mathrm{B}$, Nuclear Factor kappa-light-chain-enhancer of activated B cells; PPAR- $\gamma$, peroxisome proliferator-activated receptor gamma; STAT, signal transducer and activator of transcription; TGF, tissue growth factor; TLR, toll-like receptor; TNF, tumor necrosis factor; VEGF, vascular endothelial growth factor.

utilizing TAMs as the carrier for anti-cancer drugs (27). A detailed assessment of TAMs and pathways by which TAMs are involved in lung cancer progression can shed some light on designing novel drugs for lung cancer with a focus on TAMs.

In this review, we aim to describe pathways involved in macrophage polarization and discuss hopeful researches in TAM targeting strategies with a focus on lung cancer that leads to suppression of cancer progression and metastasis and improves patient prognosis. To obtain relevant literature, we searched Medline (via PubMed) using keywords "lung cancer", "macrophage", and "TAM" from the inception of the database to March 2020. Our search was restricted to publications in English language. We retrieved other eligible studies by manual searching of the reference lists of included studies.

We present the study in accordance with the Narrative Review reporting checklist (available at http://dx.doi. org/10.21037/tlcr-20-1241).

\section{TAMs and lung tumor growth}

Macrophages are involved in all stages of tumor progression. From the early pre-invasion stage, tumor cells attract macrophages and other inflammatory cells into the tumor stroma through the release of cytokines and exosomes (28), and in this place, macrophage directly evokes the tumor growth, migration, and metastasis (29). 
Despite the fact that alveolar macrophages are increased and constitute the main cellular component in the bronchoalveolar lavage fluid of lung cancer patients $(30,31)$, they may show diminished phagocytic abilities (32) and reduced expression of markers characteristic of M1 macrophages such as HLA-DR, CD83, and ICAM-1 $(32,33)$. In addition, alveolar macrophages in lung cancer patients secrete lower levels of inflammatory cytokines such as IL- 1 and TNF- $\alpha$ (32).

M2 TAMs induce invasion and progression of tumor cells, which lead to poor prognosis in NSCLC patients $(34,35)$. TAMs release some molecules such as matrix metalloproteinases (MMPs), growth factors, cytokines, chemokines, and other inflammatory mediators to create an inflammatory environment and drive tumor growth (36-38). Many of these molecules, like vascular endothelial growth factor (VEGF), platelet-derived growth factor (PDGF), and IL-10 are related to lung cancer progression and metastasis. VEGF-C not only affects tumor migration and angiogenesis but also promotes tumor progression and development through autocrine and/or paracrine pathways (39). Macrophages enhanced the expression of IL-8 in A549, CL1-0, CL1-5, and PC14 lung cancer cell lines. There was a certain correlation between macrophage infiltration density, and intra-tumor microvessels, and also a negative correlation with the survival of patients with NSCLC (40). Studies in lung cancer demonstrated that during tumor formation, TAMs expressed M1 markers (41), and macrophage phenotype switching from M1 into M2 occurred during lung cancer progression $(41,42)$. Yuan and colleagues revealed that $\mathrm{M} 2 \mathrm{a}$ and $\mathrm{M} 2 \mathrm{c}$ raised invasion and xenograft tumor growth of A549 cells, whereas M1 macrophages significantly decreased the expression of fibrinogens and TGF- $\beta$, which support tumor progression in the cancer cells (43). Some studies have shown that upregulation of IL-10 in M2 TAMs in NSCLC and other malignancies are associated with poor prognosis, and overexpression of IL-10 in TAMs showed a positive correlation with the late stage of NSCLC (44-46). IL10 provides tumor cells an immunosuppressive milieu by interacting with regulatory $\mathrm{T}$ lymphocytes (47). In addition, IL-10 confers resistance to apoptosis in Lewis lung carcinoma (LLC) cells (48).

Several reports of the association between macrophage density in lung tumor and patients' outcomes in terms of survival produce contradicting results (49). These conflicting results may stem from the different roles of macrophage phenotypic subtypes, the micro-distribution of TAMs in tumors of lung cancer patients, variability in the characterization methods of macrophage subtypes, insufficient statistical power, or using a particular tumor stage (50-52). A number of studies have shown that M2polarized macrophage density is correlated with worse survival in lung cancer (53-56). Meanwhile, M1-polarized macrophage density is associated with better overall survival (49). The micro-distribution of TAMs in the tumor niche influences lung cancer progression. A few reports showed that the high density of $\mathrm{CD} 68^{+}$cells and $\mathrm{CD}^{2} 8^{+} \mathrm{HLA}-\mathrm{DR}^{+} \mathrm{M} 1 \mathrm{TAMs}$ in lung cancer tumor islets was associated with better overall survival, although $\mathrm{CD} 68^{+} \mathrm{CD} 163^{+} \mathrm{M} 2$ density in tumor islets was not connected with overall survival. High stromal CD68 ${ }^{+}$TAMs or $\mathrm{CD} 204^{+} \mathrm{M} 2 \mathrm{TAM}$ sere associated with poor overall survival and advanced lymph node stages, while the density of stromal CD $68^{+} \mathrm{HLA}-\mathrm{DR}{ }^{+} \mathrm{M} 1$ and $\mathrm{CD} 68^{+} \mathrm{CD} 163^{+} \mathrm{M} 2$ TAM was irrelevant to overall survival. A low fraction of islet to stromal CD68 $8^{+}$TAM displayed poor overall survival and showed that the localization of TAMs could be a prognostic predictor in NSCLC $(49,51,57)$. The most common molecular marker used to recognize TAMs is the CD68 antibody. However, this surface molecule is not only expressed by TAMs but also by other components of tumor tissue such as malignant epithelial and stromal cells (58). In addition, labeling of macrophages just based on CD68 cannot discriminate between M1 and M2 subtypes (59).

\section{Introduction to main pathways involved in macrophage polarization in cancers and take advantage of them in lung cancer researches}

Since macrophages encounter various signals in the cellular microenvironment, the molecular mechanisms behind the macrophage polarization have not been fully characterized yet $(60,61)$. However, in the most recent decade, there has been great progress in demystifying macrophage polarization under physiological and pathological conditions such as cancer. Macrophage polarization is a highly plastic process $(62,63)$. The local cytokine microenvironment control macrophage polarization. Th1 cytokines, such as IFN- $\gamma$ and TNF- $\alpha$, drive macrophages to M1 phenotype, that produce pro-inflammatory cytokines including TNF- $\alpha$, IL-6, IL-12, IL- $1 \alpha$, and IL-1 $\beta$, through which remove pathogens during infection (64). Th2 cytokines, including IL-4 and IL-13, induces macrophage M2 polarization. This is mediated by STAT6 induction via IL-4 receptor alpha activation (64). So, cytokines are considered pivotal 


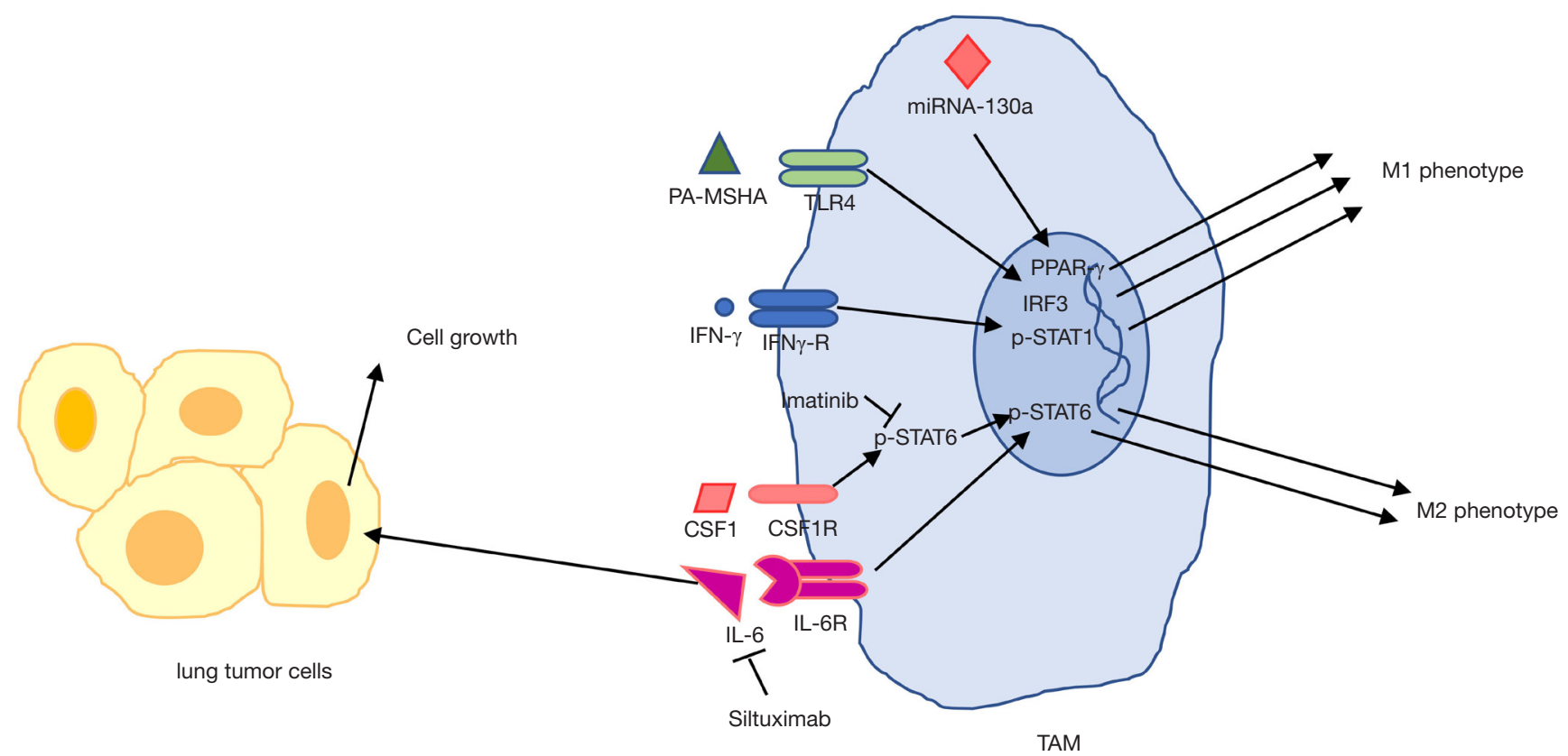

Figure 2 TAM targeting in lung cancer. Induction of TLR4 and IFN- $\gamma$ receptor by their agonists skewed TAMs into anti-tumoral M1 phenotype. miRNA-130a by targeting PPAR- $\gamma$ transcription factor regulates M1-related genes expression in TAMs in lung cancer. Targeting CSF1 and IL-6 by specific inhibitors prevents M2-polarized TAMs and suppresses lung cancer. Siltuximab by inhibition of STAT3 signaling prevents lung tumor growth. CSF, colony stimulating factor; IRF, interferon regulatory factor; PA-MSHA, pseudomonas aeruginosamannose-sensitive hemagglutinin; PPAR- $\gamma$, peroxisome proliferator-activated receptor gamma; STAT, signal transducer and activator of transcription.

contributors to macrophage polarization (Figure 1). Furthermore, macrophage switching is connected to the differential expression of diverse Toll-Like Receptors (TLRs) on macrophages (65).

\section{$I F N-\gamma$}

M1 macrophages augment tumor regression, while M2 macrophages promote tumor progression (66). IFN- $\gamma$, previously known as macrophage-activating factor (MAF), leads to polarization of TAMs from M2 toward M1 phenotype in the tumor niche. IFN- $\gamma$ by upregulation of cytotoxicity-associated markers like NKG2D and granzyme A/B (67), is identified as a potent agent responsible for inducing macrophage tumoricidal activity (68). IFN- $\gamma$ via its receptor activates STAT1, then phosphorylated STAT1 induces transcription of IFN- $\gamma$-related genes such as genes involving in M1 phenotype (69). Activated macrophages secrete IL-12 (70,71). IL-12 evokes NK and Th1 cells to produce IFN- $\gamma$, while IFN- $\gamma$ itself induces the production of IL-12 (72). It is reported that IL-12 overexpression can reverse M2 macrophage to M1 (73). In lung cancer patients, plasma IFN- $\gamma$ levels were considerably dropped (74). TAMs in IFN- $\gamma^{-/-}$mice polarized into M2 phenotype, and those mice developed larger lung tumors than those in control mice (75). Several studies have shown the beneficial effects of IFN- $\gamma$ in lung cancer inhibition. Low levels of this cytokine can induce tumor cell stemness through the ICAM1-PI3K-Akt-Notch1 pathway, whereas a high level of IFN- $\gamma$ induced apoptosis in NSCLC via the JAK1-STAT1-caspase pathway (76). Recombinant IFN- $\gamma$ enhanced the cytotoxic effects of TAMs through TNF- $\alpha$ and NO in lung cancer patients (77). A study by Ren and colleagues indicated that IFN- $\gamma$ and/or celecoxib can modulate $M 2 / M 1$ macrophage ratio in the tumor microenvironment that may prevent lung tumor growth (26). This study revealed that IFN- $\gamma$ via $\mathrm{p}-\mathrm{STAT} 1$ activates transcription of M1-related genes (26). In another study, it was concluded that IFN- $\gamma$, in combination with TLR agonists like LPS activates the M1 phenotype to inhibit LLC cell growth (78) (Figure 2). These data suggest that IFN- $\gamma$ can reprogram TAMs and switch them toward 
the M1 subtype, which improves tumor elimination. So, this protein can play a fundamental role in host antitumor immunity (69).

\section{Interleukin-6}

M2-polarized macrophages in lung cancer can secrete some interleukins such as IL-6 (79,80), IL-8 (80), and IL10 (81) to promote tumorigenesis and metastasis. IL-6 is reported as a cytokine which primes macrophages for M2 polarization through stimulating IL-4 receptor expression (82). IL-4 receptor activates STAT6, even though other STATs may also be involved (83) (Figure 2). In another hand, TAM-derived IL-6 promoted mouse lung tumor through activation of STAT3 (84). Anti-IL-6 receptor monoclonal antibody abrogated the ability of triple-negative breast cancer cell (MCF-10A) to induce M2 phenotype in macrophages (85). Targeting IL-6 and IL-6 receptor using monoclonal antibodies Siltuximab and Tocilizumab in a K-ras mutant mouse model for lung cancer suppressed cancer progression via inhibition of STAT3 tyrosine phosphorylation $(86,87)$ and polarized macrophages towards an anti-tumor phenotype (87). A study showed that IL-6 via STAT6 signaling polarized macrophages towards IL-4-dependent M2 phenotype by IL-4 receptor overexpression (82). Although the mechanism of Siltuximab action in TAM repolarization in lung cancer was not elucidated, it may work through blocking a similar mechanism. A phase I clinical trial showed acceptable safety profile of Tocilizumab in combination with chemotherapy and IFN- $\alpha 2 \mathrm{~b}$ in recurrent epithelial ovarian cancer (88). A small phase II randomized clinical trial on patients with high-risk smoldering multiple myeloma showed moderately increased progression-free survival with Siltuximab treatment (43 patients) in comparison with placebo (42 patients) (89). Several antibodies against IL-6 in lung cancer showed beneficial effects in lung cancer patients, although their roles in the re-education of TAMs have not been examined. ALD518, a humanized anti-IL-6 antibody, was examined in a randomized phase II clinical trial for NSCLC and showed preliminary evidence of efficacy for this population (90).

\section{Myeloid colony-stimulating factors}

Granulocyte-macrophage colony-stimulating factor (GM-CSF), also called CSF2 and Macrophage ColonyStimulating Factor (M-CSF), also called CSF1 are known cytokines involved in the regulation of macrophage polarization. The major function of myeloid colonystimulating factors is regulating the proliferation and differentiation of committed hematopoietic cells. GM-CSF is linked to M1 phenotype activation, and $\mathrm{M}-\mathrm{CSF}$ is associated with M2 macrophage phenotype differentiation (91). Interaction of M-CSF with its cognate receptor CSF-1R leads to upregulation of PLC- $\gamma 2$, STAT3, and Erk1/2 (92). Induction of GMCSF receptor recruits JAK2 and leads to STAT5, ERK, AKT, NF- $\kappa B$, and IRF5 activation (93). Many of these regulator molecules are also part of TLR and IFN- $\gamma$ signaling pathways. GM-CSF induces IL-6, IL$8, \mathrm{M}-\mathrm{CSF}, \mathrm{G}-\mathrm{CSF}$, TNF, and IL- $1 \beta$ in macrophages and monocytes (91). Although M-CSF and GM-CSF receptors share some common signaling pathways, they result in different transcriptional regulation and ultimate functional changes. For instance, both M-CSF and GMCSF activate Ras/MAPK pathway in macrophages to upregulate the expression of scavenger receptor (SR)-A; However, M-CSF-mediated upregulation of SR-A is caused by binding of AP-1 to the enhancer of SR-A gene but GM-CSF increases the expression of SR-A through a different enhancer region (94). While IRF5 is implicated in GM-CSF-induced M1 macrophage phenotype, IRF4 orchestrates M2 macrophage polarization by M-CSF (95). A few studies reported high serum levels of M-CSF could be a biomarker in NSCLC patients $(96,97)$. A study showed that TAMs with high expression of CSF1R were associated with a high death rate in lung cancer patients (98).

Both cytokines can be potent therapeutic targets for manipulation in human diseases such as cancer. A study demonstrated that Imatinib, by targeting CSF1R, prevented M2 polarization of TAMs in primary lung tumor or metastatic sites via inhibition of STAT6 phosphorylation (99) (Figure 2). Recombinant GM-CSF therapy promotes the anti-tumor activity of TAMs in lung cancer patients (100). CSF1R inhibitors may deplete M2 TAMs in a tumor microenvironment or modulate M1/M2 TAM ratio (101) (Figure 2). Several clinical trials are testing different classes of CSF-1R targeting agents in combination with cancer immunotherapy agents in various cancers such as NSCLC. Pexidartinib (NCT02452424) (102), classified as a small molecule kinase inhibitor, and ARRY-382 (NCT02880371) and Emactuzumab (NCT02323191), monoclonal antibodies (101), have been used for targeting CSF1R in NSCLC. 


\section{TLRs}

TLRs are a class of pattern recognition receptors, which detect molecules of invading pathogens and are pivotal for innate immunity and inflammatory responses (103). Upon activation of TLRs, they transmit a signal through adaptor molecules and downstream mediators to regulate gene expression and induce pro-inflammatory responses (104). Alterations in the metabolic profile of macrophages alter their function and activation state. It is suggested that metabolic reprogramming can be induced via TLRs and influences activation, maturation, and immunogenicity of macrophages (105). Signal transduction through TLR1/2/4 in macrophages leads to mitochondrial Reactive Oxygen Species (ROS) production, which enhances the bactericidal function of macrophages (106).

It has been revealed that TLR $4 / 5 / 7 / 8$ and 9 are overexpressed in NSCLC than in normal lung tissue (107-110). TLR4 is activated by bacterial LPS and cationic polymers. TLR4 agonists through activation of Activator Protein-1 (AP-1) and interferon regulatory factor-3 (IRF-3) cascade, trigger activation of M1 phenotype-associated genes (111). It was shown that TLR4 signaling via NF-кB in TAMs is implicated in tumor promotion in experimental lung metastasis model (112). TLR2 is an important receptor for M2b phenotype polarization in vitro (113). Lewis lung carcinoma cell line-conditioned medium stimulates TNF- $\alpha$ production by macrophages through TLR2 activation, and in consequence, it promotes lung cancer progression (114). The overexpression of TLR7 is highly associated with tumor progression, poor clinical outcomes, and chemotherapy resistance in NSCLC (110). It has been suggested that TLR7 acts as a mediator of switching to M2 macrophage phenotype (65). Other TLR inducers like lipoteichoic acid (LTA) (115), R848 (116), and CpG (117) have potency for induction of antitumor M1 macrophages.

TLR signaling cascade regulates pro-inflammatory gene expression through activation of STAT1 and NF- $\kappa \mathrm{B}$ (118). STAT1 has been proved to be a crucial regulator of biological responses of various TLRs. TLR/ $\mathrm{NF}-\kappa \mathrm{B}$ axis is a vital signaling pathway in the regulation of macrophage polarization (119). In most cases, TLR/ NF- $\kappa \mathrm{B}$ activation promotes M1 macrophage phenotype. However, this depends on NF- $\kappa \mathrm{B}$ subunit composition. For instance, NF-kB p65/p50 heterodimer boosts proinflammatory cytokines, and M1 macrophages are generated (120) while p50/p50 homodimer induces M2 macrophage phenotype (61).
Pseudomonas aeruginosa-mannose-sensitive hemagglutinin (PA-MSHA) through TLR4 activation reeducated M2 macrophage towards M1 in the malignant pleural effusion of lung cancer, and TLR4 blocking prevented this effect (121). Some studies confirmed the influence of PA-MSHA for advanced lung cancer treatment $(111,121,122)$ (Figure 2). SPC-A1 NSCLC cell line in co-culture with TAMs overexpressed TLR1/6/7, and pretreatment with agonist ligands for these receptors led to induction of IL-1 $\beta$, IL-8, and IL-6, which supported the inflammatory microenvironment and promoted the development and progression of lung cancer (116). The combination of Motolimod (a TLR8 agonist) with PEGylated liposomal Doxorubicin did not prolong overall survival or progression-free survival of recurrent ovarian, fallopian tube, or primary peritoneal carcinoma over placebo and PEGylated liposomal Doxorubicin in a phase II randomized clinical trial (123). EMD1201081 (a TLR9 agonist) and Cetuximab did not have superior efficacy than Cetuximab monotherapy in patients with recurrent or metastatic squamous cell carcinoma of head and neck revealed by a phase II randomized clinical trial (124). A phase I dose-finding trial enrolling previously-treated NSCLC patients showed acceptable safety and moderate overall response (15\%) of IMO-2055 (a TLR9 agonist) with Erlotinib and Bevacizumab (125). Although a few researches have been performed in the manipulation of TLR pathways of macrophages in lung cancer for therapeutic aims, this pathway could open novel avenues for finding new approaches in the suppression of lung cancer.

\section{PD-1/PD-L1 immune checkpoints}

Programmed cell death protein 1 (PD-1)/PD-1 ligand (PDL) pathway plays an important part in establishing an immunosuppressive environment in the tumor and the evasion of cancer cells from anti-cancer immune responses. Of relevant clinical importance, PD-1/PD-L1 inhibition using blocking antibodies is being used for the treatment of many cancer types including melanoma, renal cell carcinoma, NSCLC, SCLC, squamous cell skin cancer, and triple-negative breast cancer (126). Tumor-infiltrating macrophages may express both PD-1 and PD-L1 (127). The anti-tumor effects of PD-1 and PD-L1 blocking antibodies were reversed following TAM depletion by antiCSF1R antibody in a mouse model of colon cancer (CT26 cell line) (128); Hence, TAMs are significantly involved in the immunosuppressive potentials of $\mathrm{PD}-1 / \mathrm{PD}-\mathrm{L} 1$ 
pathway in cancerous microenvironment. The majority of PD $-1^{+}$tumor macrophages display M2 phenotype. PD- $1^{+}$ macrophages show defective phagocytic function in comparison with $\mathrm{PD}-1^{-}$macrophages (128). Interferonsensitive responsive element (ISRE), STAT1, and STAT2 are pivotal for PD-1 expression in TAM (129).

TAMs are the most abundant PD- $1^{+}$immune cells in human NSCLC stroma (130). While PD-L1 is mostly recognized for its inhibitory effects on $\mathrm{T}$ cells through interacting with PD-1 (126), it seems that the main function of PD-L1 in TAM is skewing macrophage polarization towards an immunosuppressive state. There is evidence that PD-L1 affects TAM function through downregulating Akt/mTOR pathway (131). Additionally, TAMs that crosspresent cancer antigen can evade immune destruction by $\mathrm{T}$ cells in a PD-L1 dependent manner (132). Pyruvate Kinase (PK) M2 isoform and Secreted Phosphoprotein 1 (SPP1) are the intracellular regulators of $\mathrm{PD}-\mathrm{L} 1$ expression in TAM $(133,134)$. To sum up, PD-1 and PD-L1 proteins are involved in regulating macrophage polarization.

PD-1/PD-L1 pathway has clinical implications in NSCLC. PD-L1 expression, both in cancer cells and TAMs, was inversely associated with survival in early-stage NSCLC (135). The high density of PD-L1 ${ }^{+}$TAM in tumor tissue predicted better survival in NSCLC patients who were treated with PD-1/PD-L1 inhibitors (130). PD-1/PD-L1 immune checkpoint inhibitors such as Pembrolizumab, Atezolizumab, and Nivolumab, either as single-agent or in combination with chemotherapy, have shown clinical efficacy in PD-L1 ${ }^{+}$ NSCLC (136-139). In conclusion, clinical application of PD-1/PD-L1 pathway has come of age for NSCLC.

\section{Role of miRNAs in macrophage polarization:}

Micro RNAs (miRNAs) are small non-coding RNAs that are able to regulate gene expression by binding to target messenger RNAs (mRNAs) that either lead to their decay or translation inhibition (140). miRNAs have long been known for their different roles in development, differentiation, and homeostasis (141). A great body of studies has suggested the involvement of miRNAs in the macrophage polarization in human and murine-derived macrophages $(142,143)$. Functional miRNAs that are involved in polarizing macrophages have been identified (144). Namely, miRNA$125 \mathrm{~b}$ decreases the level of IRF4 by targeting it. IRF4 is a key signaling molecule for the induction of $\mathrm{M} 2$ phenotype. In line, miRNA-125b overexpression in macrophages potentiates their antigen-presentation capabilities, priming of T cells, and cancer cell killing (145). The overexpression of miRNA-720 reprograms TAMs toward M1 phenotype by targeting GATA3 (146) (Table 1).

Neutrophils of high-risk heavy smokers secrets circulating miRNA-320a that through downregulation of STAT4 in macrophages promoted M2-like macrophage in lung cancer (180). It has been reported that miRNA130a repolarized M2 macrophage towards M1 phenotype and had a prognostic role in NSCLC. Downregulation of miRNA-130a was correlated with poor overall survival, tumor progression, and metastasis in NSCLC patients (158) (Figure 2). Jingushi and colleagues reported that upregulation of miRNA-130b in NSCLC tissue specimens was associated with poor overall survival in patients suffering from NSCLC (181). miRNA-155 expression showed a prognosis role in patients with NSCLC and digestive system carcinomas (182). According to the link between miRNAs, immunosurveillance, and cancer progression, miRNA targeting could promote the development of new therapeutic strategies or diagnostic and prognostic tools in NSCLC.

\section{Role of extracellular vesicles in macrophage polarization}

Extracellular vesicles are membrane-bound structures that originate from cells and can be endocytosed by other cells. These vesicles contain macromolecules such as DNA, RNA, and proteins and the transfer of macromolecules between cells by the means of extracellular vesicles provides an intricate mode of intercellular communication and tissue and systems-level homeostasis. Intriguingly, neoplastic cells utilize extracellular vesicles for regulating the functions of other malignant cells, tumor microenvironmental cells, cells related to hematopoiesis, and distant organ niche. The main categories of animal extracellular vesicles are exosomes (30-120 nm), microvesicles (100-1,000 nm), and apoptotic bodies (800-5,000 nm) (183). Cancer cellderived extracellular vesicles can promote M2 macrophage polarization. Non-coding RNAs including miRNA103a, miRNA-25-3p, miRNA-130b-3p, miRNA-425$5 \mathrm{p}$, and miRNA-301a-3p were present in lung cancer cell (CL1-5, NCI-42087, H1792, and H1437), colon cancer cell (HCT116), and pancreatic cancer cell (PANC1)derived extracellular vesicles. These miRNAs targeted and decreased the level of PTEN which resulted in M2 macrophage polarization through STAT3 activation (184-186). Exosomes acquired from hypoxic epithelial 
Table 1 Functional miRNAs regulate macrophage polarization

\begin{tabular}{|c|c|c|c|}
\hline miRNAs & Promoted phenotype & Target(s) & Reference(s) \\
\hline miRNA-27a & M1 & PPAR- $\gamma$ & $(150)$ \\
\hline miRNA-27b & M1 & PPAR- $\gamma$ & (151) \\
\hline miRNA-125a & M1 & IRF4 & (152) \\
\hline miRNA-21 & M1 & STAT3 & (153) \\
\hline miRNA-127 & M1 & Bcl-6, Dusp1, JNK & (154) \\
\hline miRNA-720 & M1 & GATA3 & $(146)$ \\
\hline miRNA-223 & M1 & Pknox1 & (155) \\
\hline miRNA-125b & M1 & IRF4 & $(145)$ \\
\hline miRNA-130a & M1 & PPAR- $\gamma$ & (158) \\
\hline miRNA-130b & M1 & PPAR- $\gamma$ & (159) \\
\hline miRNA-125a & M2 & KLF-13 (in mice) & $(160)$ \\
\hline miRNA-34a & M2 & Notch1 & $(161)$ \\
\hline miRNA-146a & M2 & INHBA, TLR4/IRF3, IRAK1, TRAF6 & $(162-165)$ \\
\hline miRNA-146b & M2 & & $(166)$ \\
\hline miRNA-223 & M2 & PBX/Knotted1 Homeobox 1 (Pknox1), STAT3 & $(167)$ \\
\hline miRNA-124 & M2 & C/EBP- $\alpha$, STAT3, TACE & $(174,175)$ \\
\hline miRNA-145 & M2 & IL10 gene silencer histone deacetylase 11 & $(176)$ \\
\hline miRNA-93 & M2 & IRF9 & $(177)$ \\
\hline miRNA-21 & M2 & $\mathrm{SIRPb} 1$ & $(178)$ \\
\hline Let-7c & M2 & C/EBP- $\delta$, PAK 1 & $(162,172)$ \\
\hline miRNA-181a & M2 & KLF6, C/EBP- $\alpha$ & $(179)$ \\
\hline
\end{tabular}

ovarian cancer cells (SKOV3) harbored miRNA-21-3p, miRNA-125b-5p, miRNA-181d-5p, and miRNA-222-3p which degraded SOCS in macrophages and subsequently increased phosphorylated STAT3, a process which culminated in M2 macrophage polarization $(171,187)$.
In addition, STAT6 upregulation mediated by cGAS/ STING pathway is reported to be involved in cancer cellderived extracellular vesicle-induced M2 macrophage polarization (188). Exosomes derived from DLD-1 colon cancer cell line contained miRNA-145 which polarizes 
TAMs towards M2 phenotypes by downregulating histone deacetylase 11 (189).

In a study by Chen et al., extracellular vesicles derived from lung cancer cell lines (HCC827, LLC, A549, and H460) were taken up by macrophages and promoted M2-like phenotype in TAMs. These TAMs produced IL-1 $\beta$ which enhanced lung cancer cell stemness and survival. It was revealed that lung cancer cell-derived microparticles contained non-coding RNAs that could stimulate TLR3 activation which subsequently increased pro-IL-1 $\beta$ expression in a NF- $\kappa \mathrm{B}$ and MAPK-dependent pathway. Simultaneously, extracellular vesicles uptake by macrophages increased cytosolic calcium concentration and mitochondrial ROS production. ROS activated NLRP3 inflammosome which is required for IL- $1 \beta$ activation (190). In another study, the E3 Ubiquitin ligase TRIM59 was delivered to macrophages by lung cancer cell line (H1299 and A549)-derived exosomes. TRIM59 promoted ubiquitination and proteasomal degradation of ABHD5, a hydrolase enzyme which is involved in lipid metabolism. Downregulation of ABHD5 activated NLRP3 inflammosome and resulted in enhanced IL- $1 \beta$ production (191). Collectively, these studies demonstrate the cardinal role of extracellular vesicles in regulating macrophage polarization.

\section{Macrophage immunotherapy in cancer}

As a matter of macrophage contribution to tumor growth, angiogenesis, and metastasis, there has been remarkable attention in macrophage therapy. Macrophage immunotherapy can be divided into those that reduce the number of TAMs in the tumor microenvironment by targeting TAM recruitment or survival and reduce circulating monocytes that are the progenitor of TAMs, those that reprogram activities of TAMs and using macrophages as carriers of anti-cancer drugs. Novel therapeutic approaches target survival, recruitment, polarization, and other properties of TAMs in cancer progression. Combinatorial approaches have emerged and shown efficacy in preclinical studies (58). These strategies are currently in assessment either to increase tumor immunity during standard radio- or chemotherapy or in combination with $\mathrm{T}$ cell-mediated immunotherapy (192). We will discuss some potential pathways that can be translated into therapeutic strategies to inhibit TAMmediated immune suppression. Table 2 summarizes the main molecular pathways that have been employed for TAM targeting in clinical trials so far.

\section{Targeting TAM recruitment and survival}

One method to diminish the number of TAMs in the tumor microenvironment is preventing their replenishment by circulating inflammatory monocytes. Monocytes are mainly dependent on CCL2-CCR2 signaling for migration from the bone marrow and recruitment towards inflammatory centers. Therefore, CCL2-CCR2 inhibition limits them in the bone marrow and reduces the number of TAMs in primary and metastatic sites (230). In preclinical models, inhibition of these targets improves the efficacy of chemotherapy, radiotherapy, and immunotherapy (231). A study indicated that PF04136309, a CCR2 antagonist, prevents the movement of CCR2 + monocytes from bone marrow to the tumor, which causes TAM depletion (232). CCL2 blockade using specific antibodies showed effective results in combination with chemotherapy in various cancer models such as lung, prostate, and liver neoplasms (233-235). Crosstalk between TAMs and lung cancer cells through CCR2 could play a critical role in lung tumor proliferation and metastasis. CCR2 antagonist (RS504393) treatment LLC murine model showed diminished primary tumor growth and metastasis and inhibited TAM accumulation (236). Anti-CCL2 monoclonal antibody reduced primary tumor growth in syngeneic flank and orthotopic animal models of NSCLC and suppressed lung metastases in spontaneous lung metastases of NSCLC. Although the CCL2 blockade did not influence the number of TAMs recruited into the tumor in this study, there was a significant decrease in the M2 macrophage phenotype (233).

The CSF1-CSF1R axis is another target pathway of interest for inhibition of TAM recruitment to tumor microenvironment in preclinical models. This axis is important for differentiation, survival, and recruitment of TAM (237). In numerous tumors, blockage of CSF1CSF1R signaling leads to the elimination of a remarkable portion of TAMs or repolarization of them $(101,238,239)$. In animal models, CSF1 R blockage improves $\mathrm{T}$ cell responses in combination with chemo- and radiotherapeutic agents (240-242). The combination of CSF1 and/or CSF1R blockage with immune checkpoint inhibitors such as CD40 agonists, PD-1 or CTLA4 antagonists, and T cell therapy is a promising spot in TAM therapy $(243,244)$. Small molecule CSF1R inhibitor BLZ945 in phase I/II clinical trial (NCT02829723) is being tested for advanced solid 
Table 2 Clinical trials of potential drugs for TAM targeting

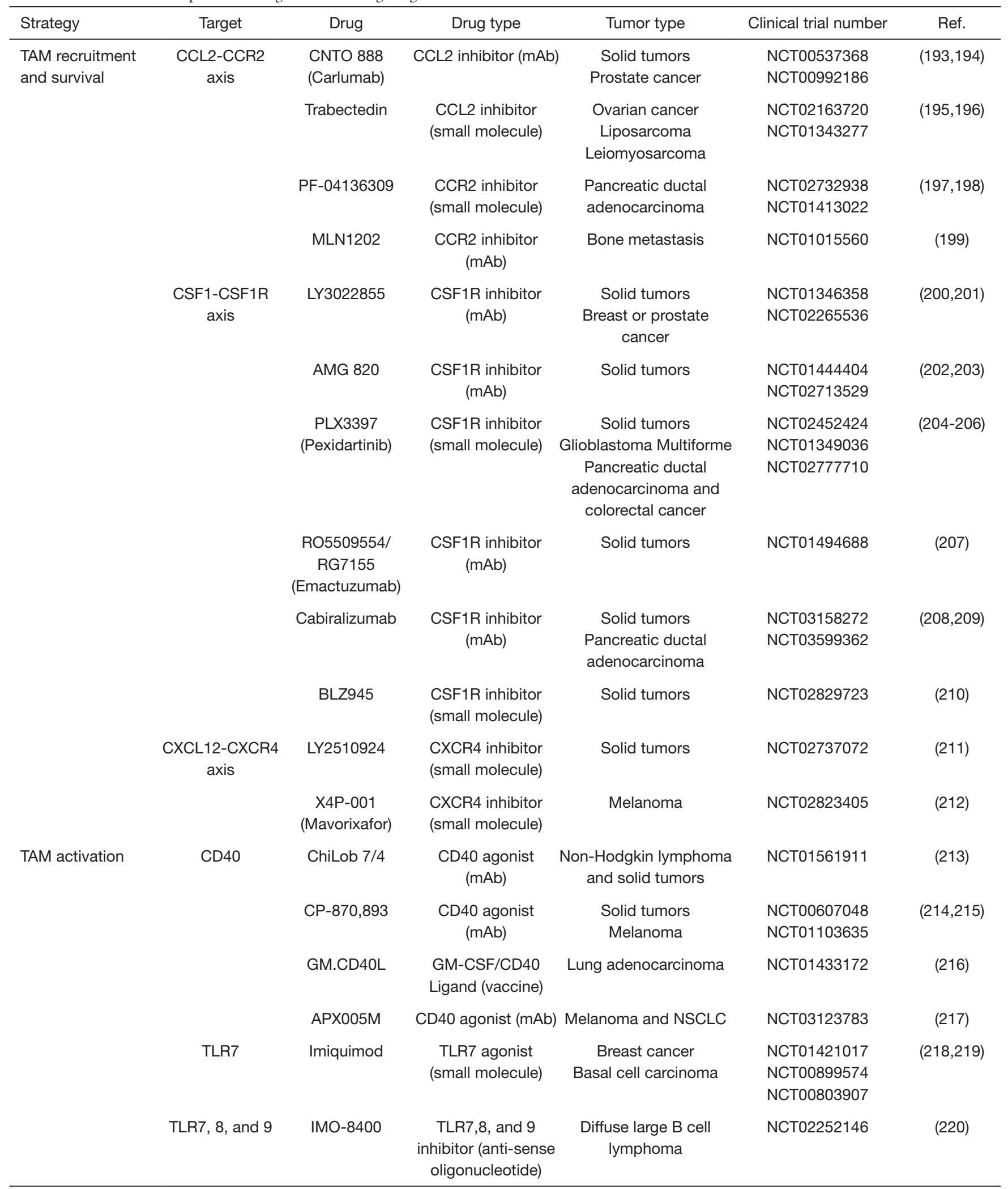

Table 2 (continued) 
Table 2 (continued)

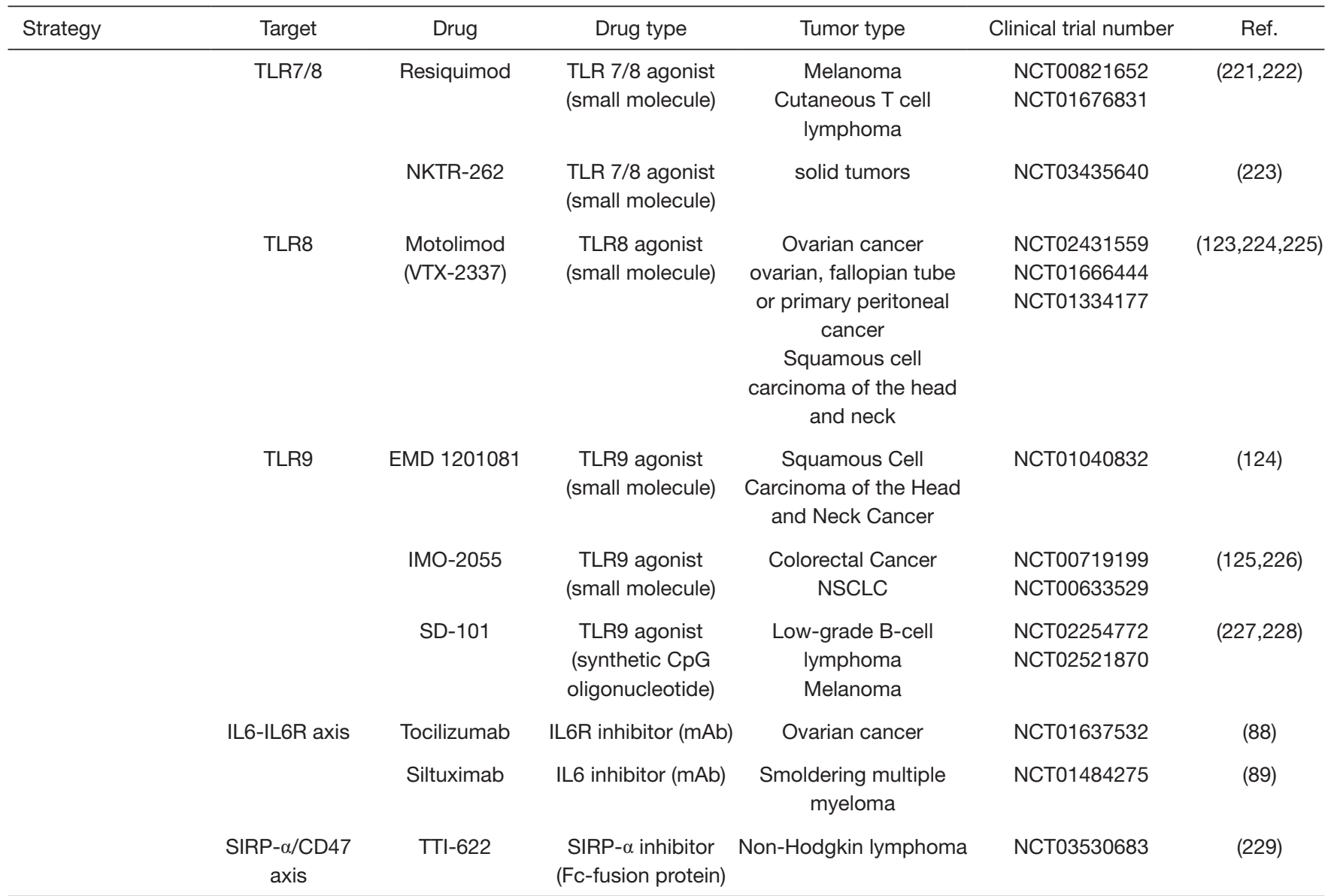

CCL C-C, motif chemokine ligand; CCR C-C, chemokine receptor; CD, cluster of differentiation; CSF, colony stimulating factor; CXCR, C-X-C chemokine receptor; GM, granulocyte-macrophage; IL Interleukin; mAb, monoclonal antibody; NSCLC, non-small cell lung carcinoma; TLR, toll-like receptor; SIRP, signal regulatory protein.

tumors such as lung cancer (245). This inhibitor limited the experimental LLC-induced malignant pleural effusion model (246). Pass and colleagues showed that CSF-1R inhibitor JNJ-40346527 reduced expression of genes related to epithelial-to-mesenchymal transition (EMT), stem cell markers, and cisplatin resistance genes in multiple lung cancer CSF-1R positive cell lines (A549, NCI-H1299, NCI-H157, CALU-1, NCI-H1975, NCI-H358, and NCI-H4660) (247).

Another signaling pathway that is involved in macrophage recruitment is CXCL12-CXCR4. CXCL12CXCR4 inhibition in combination with radiotherapy and immunotherapy has displayed anti-tumor efficacy, and this axis has emerged as a target to intervene with the immune system in clinical trials (248). Selective CXCR4 antagonists have been developed by some pharma companies that can be divided into four major classes: (I) small peptide CXCR4 antagonists such as BL-8040 and T140, (II) non-peptide CXCR4 antagonists such as AMD3100 and AMD070, (III) antibodies against CXCR4 such as LY2624587, and (IV) modified agonists and antagonists for CXCL12 such as CTCE-0214 and CTCE-9908, respectively $(249,250)$. The expression of CXCR4 is high in lung cancer, specifically in SCLC. It has been shown that administration of AMD3100, in monotherapy or in combination with standard chemotherapy composed of etoposide and cisplatin, diminished the proliferation of SCLC primary tumor and inhibited metastasis in a xenograft mouse model (251).

Despite the beneficial aspects of these kinds of studies, tumor microenvironment can lead to the development of resistance to targeted pathways. Longterm administration of CSF-1R inhibitor BLZ945 in the animal model of Glioblastoma Multiforme (GBM) developed acquired resistance to CSF-1R inhibition by 
elevated phosphoinositide 3-kinase (PI3K) signaling that led to disease recurrence without tumor cell intrinsic modifications (252). Compensatory resistance pathways and loss of tissue-resident macrophage populations, which are crucial for maintaining homeostasis, limit the application of these methods in clinical trials (192).

\section{Targeting TAM activation}

Another strategy in macrophage immunotherapy is the inactivation of macrophage immune-stimulatory activities as the primary phagocyte and professional antigen-presenting cell inside tumors. Reprogramming or macrophage repolarization towards an anti-tumor phenotype can be an effective approach to enhancing the efficacy of other types of immunotherapy.

Targeting the main molecular pathways which drive the immunosuppressive effects of M2-like phenotype TAMs, such as IL-4, IL-10, and IL-13, can be utilized as effective therapies against the pro-tumorigenic subtype of TAMs in cancers $(58,253)$. IL-10 showed a close association with M2 TAMs, and it is reported that upregulation of IL-10 in TAMs correlates with late stage of lung cancer (46). IL-10 in cultured human macrophages induces chemoattractants, pattern recognition receptors such as TLRs, macrophage receptor with collagenous domain (MARCO), and cytokine receptors (254). MARCO drives macrophages towards immunosuppressive phenotype M2. In human melanoma samples and B16 melanoma murine tumors, MARCO is broadly expressed by TAM, and anti-MARCO antibody treatment significantly reduces the rate of a distinct TAM population that expresses arginase 1 (ARG1) and inhibits in vitro $T$ cell proliferation (255).

TAM receptors, including Tyro3, Axl, and MERTK, are a group of tyrosine kinase receptors with common ligands Gas6 and Protein S. They stimulate macrophage polarization toward M2-like phenotype (256). Some studies have reported overexpression of Axl and MERTK in some cancers such as NSCLC (257-259). Small molecule inhibitor of MERTK, UNC2025, decreased tumor xenograft growth in the murine model of NSCLC (260).

TAMs express a membrane glycoprotein called Signal Regulatory Protein-alpha (SIRP- $\alpha$ ). Interaction of SIRP- $\alpha$ with CD47 on cancer cells inhibits cancer cell phagocytosis by TAMs (261). Inhibition of SIRP- $\alpha$ by blocking antibody prevented the development of resistance to anti-angiogenic therapy in the mouse model of NSCLC (262). Mechanistic studies revealed that antibodies against SIRP- $\alpha$ increased the phagocytic function of TAMs and macrophage-mediated cytotoxicity against cancer cells $(262,263)$. CD 40 signaling is implicated in monocyte maturation and differentiation into M1 macrophage and dendritic cells and can re-educate M2 phenotype macrophages into M1. Targeting CD40/CD40L is a common strategy in cancer immunotherapy (264). CD40L gene transfer into 3LLSA murine lung cancer cells increased the anti-tumoral activity of TAMs and stimulated the production of NO, TNF- $\alpha$, and IL-12 (265). Pilot clinical trials of CD40 agonist antibodies in combination with chemotherapy or immune checkpoint inhibitors have shown acceptable safety profile and preliminary response in a variety of solid tumors including NSCLC $(213-215,217)$.

Epigenetic reprogramming of macrophages by inhibition of histone deacetylases (HDACs) can elicit a T cell supportive role. M2 macrophages express HDAC2, and its inhibition leads to macrophage repolarization to M1 phenotype (266). Inhibition of this enzyme using genetic approaches (siRNA) or pharmacological inhibitors (ISAHA, VPA) in M2 macrophages and TAMs from lung tumors skewed them to M1-like phenotypes and controlled tumor cell functions (266). A selective class IIa HDAC inhibitor evokes anti-tumor macrophage phenotypes that assist $\mathrm{T}$ cell responses and augments responses to chemotherapy and immune checkpoint inhibition, particularly in mammary tumor models (267).

It has been demonstrated that activation of PI3 $\mathrm{K}_{\mathrm{r}}$ signaling leads to TAM immunosuppressive activities in models of melanoma, lung, and pancreatic cancer (268). In animal models, $\mathrm{PI} 3 \mathrm{~K}_{\Upsilon}$ blockage causes macrophage reprogramming and enhancement of $\mathrm{T}$ cell responses as a single agent or in combination with $\mathrm{T}$ cell checkpoint inhibition $(269,270)$. Imatinib, through inhibition of STAT6 phosphorylation and nuclear translocation, suppressed M2 macrophage polarization and reduced migration of LLC cells both in vitro and in vivo, although it did not influence lung tumor growth (99).

In conclusion, blocking the activating molecules of TAM is a promising strategy to enhance the efficiency of other therapies such as checkpoint inhibitor therapy.

\section{Using macrophages as a carrier for anti-cancer drugs delivery}

TAMs can be employed as a carrier for anti-cancer drug delivery systems (Figure 3). Some key characteristics of TAMs make them suitable for drug delivery in cancer settings. Separating circulating monocytes from peripheral 

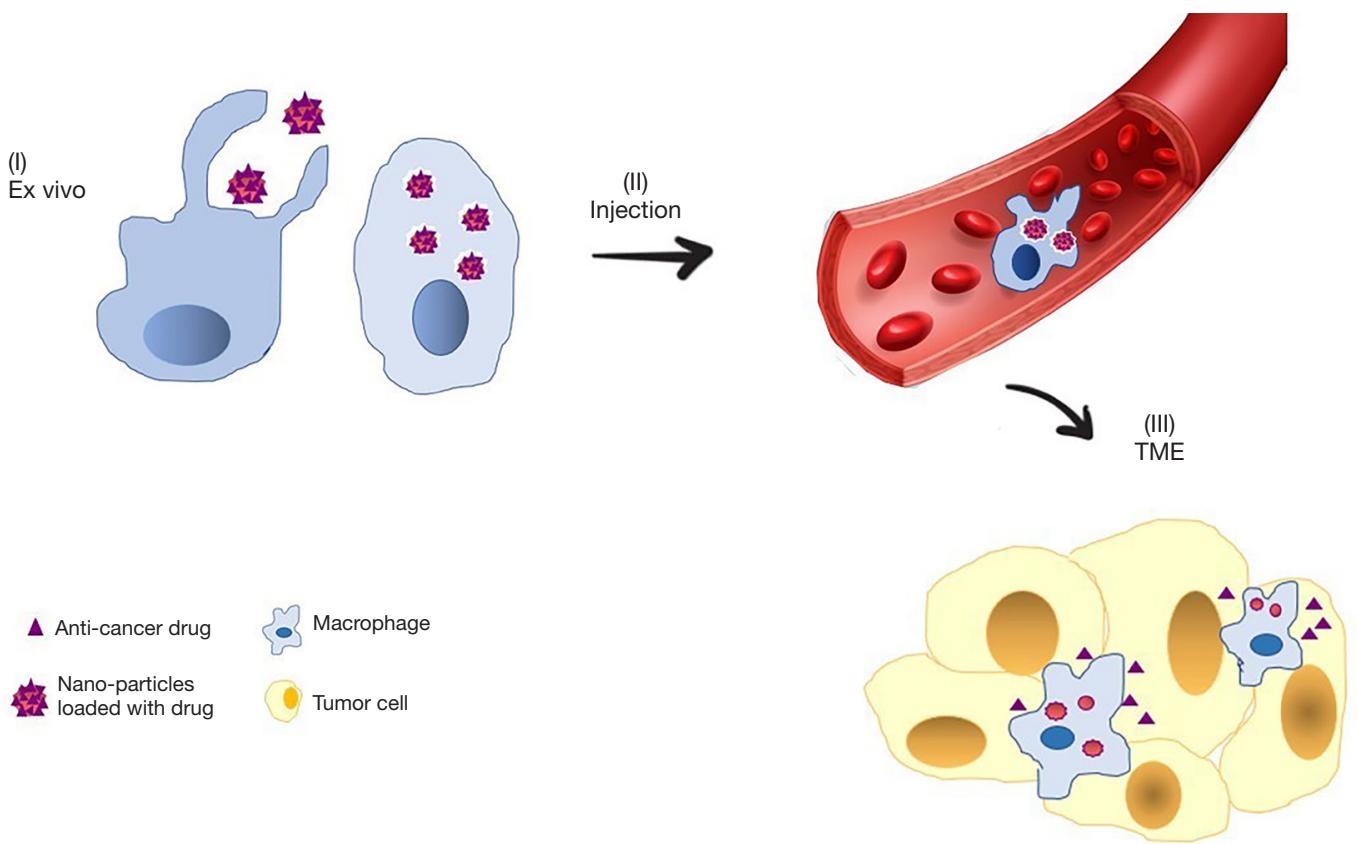

Figure 3 Macrophage-based drug delivery to tumors. (I) Nanoparticles that are loaded with anti-cancer drugs are engulfed by macrophages ex vivo. (II) Macrophages that contain nanoparticles are injected intravenously and migrate to tumors. (III) Anti-cancer drugs are released from macrophages into TME to kill cancer cells. TME, tumor microenvironment.

blood is more feasible than other cellular carriers such as mesenchymal stem cells; macrophage phagocytic property can be used for drug loading into macrophage; and they inherently home to tumor microenvironment in the body (271). M1 phenotype is usually considered as the carrier for nano-particle delivery. M1 macrophages have more phagocytic potency for loading anti-cancer drugs nano-particles than other types of macrophages and can naturally home into tumor tissues. Furthermore, the tumor microenvironment cannot influence M1 cells, and their own activity can inhibit tumor progression $(272,273)$. In a pivotal study by Choi et al., TAMs containing Gold Nano-shells moved along the central hypoxic region of breast tumor and destroyed surrounding cancer cells after irradiation with near-infrared laser waves (274). Wang and colleagues reported that monocytes internalized $\mathrm{Fe} / \mathrm{Fe}_{3} \mathrm{O}_{4}$ magnetic Nano-particles combined with topoisomerase I inhibitor SN38 by the carboxylesterase-cleavable linker and delivered them to tumors (275). Anchoring lipopolysaccharide (LPS) on macrophages mediates production of microtubule networks with A549 cells and leads to selective Doxorubicin delivery to cancer cells via intercellular microtubule conduits in orthotopic lung cancer model (276). Some limitations, including the low-load capacity of carrier, relatively low drug release, the possibility of drug cytotoxicity, and susceptibility of drugs to lysosomal degradation within macrophage have restricted the applicability of macrophages in this context (277). Further studies are needed to improve this approach and overcome its defects.

\section{Therapeutic limitations of macrophage regulation}

TAM targeting for cancer treatment is challenged by some obstacles including predisposition to infection, organ dysfunction, the need for multiple dosing, and the presence of redundant pathways. Macrophages are cardinal in protecting body from invading pathogens. TAM targeting strategies that are based on eradicating macrophages may increase susceptibility to infections. On the other hand, tissue-resident macrophages such as liver Kupffer cells and brain microglial cells are ubiquitous throughout the body and are significantly involved in maintaining organ homeostasis and their depletion may give rise to serious organ dysfunction. One possible solution for overcoming these problems is to find novel targets that are specifically upregulated by macrophages in cancerous 
microenvironment (25). Potential candidate molecules and pathways for TAM targeting may be present in diverse cell populations beyond TAM. For instance, CCR 2 and CXCR4 are also expressed by lymphocytes $(278,279)$. Alterations of immune and non-immune cellular functions caused by unintended influence on cells that share the target with TAM may result in complications. This issue also necessitates finding of targets that are specific to TAM (25).

The optimal dosing and frequency of TAM targeting therapeutics have not been determined. One special difficulty related to TAM repolarization is that TAM phenotype and function may return to its primary immunosuppressive state after the drug is withdrawn from tumor microenvironment (280).

The ultimate functional status of TAM is controlled by the complex interactions of several microenvironmental and intracellular regulators. The presence of redundant pathways of macrophage polarization and other immunosuppressive cells in tumor microenvironment may explain the observation that not all the tumors respond to TAM targeting strategies. Simultaneous interference with multiple contributors of immunosuppression and cancer progression either by combinatorial approaches or using agents with multiple relevant targets may enhance TAM targeting efficacy (192).

To conclude regarding the possible roles of TAM targeting in NSCLC, as TAMs are abundant in the tumor microenvironment of NSCLC and plays important parts in its progression, targeting TAM, either by eradicating them or re-educating them towards anti-cancer phenotype, will be a rationale strategy that can be translated to clinical application.

\section{Macrophage and drug resistance}

Drug resistance prevalently occurs against traditional chemotherapy drugs and targeted therapies in NSCLC patients $(281,282)$. Neoplastic cell-extrinsic factors are involved in cytotoxic therapy resistance (283). In vivo studies have indicated that macrophages not only support tumor growth and progression but also mediate chemotherapy resistance by providing survival factors and upregulating genes responsible for anti-apoptotic programs in malignant cells. Soluble factors secreted by macrophages, such as IL-6, as well as extracellular deposition and cell-cell interactions, are involved in chemotherapy resistance (283-285). TAMs via CSF-1 signaling pathway diminishes the effectiveness of a combination therapy using Cyclophosphamide,
Methotrexate, and 5-FU in a MCF-7 breast cancer xenograft model (286). TAMs defend MMTV-PyMT tumor cells against paclitaxel-induced cell death by secretion of lysosomal enzymes, Cathepsin B and S (287). In the animal model of colorectal cancer, TAMs mediate chemoresistance to 5 -FU through secretion of IL-6 and the activation of IL6R/STAT3 signaling (288). TAMs mediate Gemcitabine resistance in pancreatic ductal adenocarcinoma cells by upregulating cytidine deaminase, the metabolizing enzyme of Gemcitabine (289). TAMs have a supportive role in cancer stem cell functions (290). The interplay between TAMs and cancer stem cells by macrophage-derived factors, including IL-6 and Milk-Fat Globule-epidermal growth factor-VIII (MFG-E8) through activation of Hedgehog signals and STAT3 mediates drug resistance and induces distinct important maintenance signaling for cancer stem cells (291-293).

TNF- $\alpha$ is one of the crucial factors mediating chemoprotection, either directly by NF- $\mathrm{KB}$ activation (294) or indirectly through stimulated IL-6 expression and further STAT3 activation (58). Macrophages can be considered as the main source of TNF- $\alpha$ in vivo (295). In this regard, it has been documented that macrophage-derived TNF- $\alpha$ promotes resistance to MAPK inhibitors in melanoma. The protective effect of TNF- $\alpha$ on melanoma cell lines was mediated by the upregulation of the microphthalmia transcription factor (MITF) in melanoma cells (296). In a recent study, it has been demonstrated that TAMs can evoke autophagy in hepatocellular carcinoma (HCC) cell lines, which are involved in resistance to Oxaliplatin (297).

\section{Conclusions}

NSCLC is one of the most common malignancies in the world, and researchers are making considerable efforts for finding effective therapies. Unfortunately, all strategies do not work for all tumors, and all patients do not respond in the same manner to those therapies. It is partly because of tumor immunogenic properties and tumor niche composition. Increasing evidence demonstrates that TAM is one of the main components of the immune-suppressive tumor microenvironment. Since high macrophage infiltration causes poor survival in most cancers, these cells have emerged as promising aims for anticancer therapies. As briefed in this review, various studies have demonstrated that TAM targeting can synergistically improve the response to other conventional cancer treatments. However, most of these therapies are still at the preclinical stage, blocking 
antibodies or antagonists have been examined in clinical trials for malignant solid tumors (101). Studies at the preclinical level have shown that the combination of TAM targeting strategies with checkpoint inhibitors can improve the therapeutic response in melanoma, colon, lung, and breast tumors (127). One main obstacle of TAM targeting is the occurrence of negative side effects in the patients. Due to the countless roles of macrophages, it seems that systemic depletion of these cells leads to increased infections or disabled activities of tissue-resident cells to do their normal function. To overcome this obstacle, one reasonable approach is to identify TAM-specific markers in order to precisely targeting this tumor immunosuppressive cell population. Targeting TAMs in lung cancer showed promising effects in the suppression of primary tumor growth or preventing lung metastasis.

Totally, preclinical and early clinical studies show that targeting lung TAMs could remarkably enhance the efficacy of conventional therapies and immunotherapies, but there is a long way between understanding the roles and mechanisms of TAMs in lung cancer progression and using TAM-based immunotherapy to cure cancer.

\section{Acknowledgments}

Funding: None.

\section{Footnote}

Reporting Checklist: The authors have completed the Narrative Review reporting checklist. Available at http:// dx.doi.org/10.21037/tlcr-20-1241

Peer Review File: Available at http://dx.doi.org/10.21037/ tlcr-20-1241

Conflicts of Interest: All authors have completed the ICMJE uniform disclosure form (available at http://dx.doi. org/10.21037/tlcr-20-1241). The authors have no conflicts of interest to declare.

Etbical Statement: The authors are accountable for all aspects of the work in ensuring that questions related to the accuracy and integrity of any part of the work are appropriately investigated and resolved.

Open Access Statement: This is an Open Access article distributed in accordance with the Creative Commons
Attribution-NonCommercial-NoDerivs 4.0 International License (CC BY-NC-ND 4.0), which permits the noncommercial replication and distribution of the article with the strict proviso that no changes or edits are made and the original work is properly cited (including links to both the formal publication through the relevant DOI and the license). See: https://creativecommons.org/licenses/by-nc-nd/4.0/.

\section{References}

1. Bray F, Ferlay J, Soerjomataram I, et al. Global cancer statistics 2018: GLOBOCAN estimates of incidence and mortality worldwide for 36 cancers in 185 countries. CA Cancer J Clin 2018;68:394-424.

2. Inamura K. Lung cancer: understanding its molecular pathology and the 2015 WHO classification. Front Oncol 2017;7:193.

3. Ries LA, Harkins D, Krapcho M, et al. SEER cancer statistics review, 1975-2003, National Cancer Institute. Bethesda, MD. 2006. Available online: https://seer.cancer. gov/csr/1975_2003/

4. Zappa C, Mousa SA. Non-small cell lung cancer: current treatment and future advances. Transl Lung Cancer Res 2016;5:288-300.

5. Institute Nc. SEER Cancer Stat Facts: Lung and Bronchus Cancer. Bethesda, MD. Available online: https://seer. cancer.gov/statfacts/html/lungb.html

6. Ben-Baruch A. Inflammation-associated immune suppression in cancer: the roles played by cytokines, chemokines and additional mediators. Semin Cancer Biol 2006;16:38-52.

7. Karin $M$. Nuclear factor- $\kappa B$ in cancer development and progression. Nature 2006;441:431-6.

8. Joyce JA, Pollard JW. Microenvironmental regulation of metastasis. Nat Rev Cancer 2009;9:239-52.

9. Kamp DW, Shacter E, Weitzman SA. Chronic Inflammation and Cancer: The Role of the Mitochondria. Oncology 2011;25:400-10.

10. Shi L, Wang L, Hou J, et al. Targeting roles of inflammatory microenvironment in lung cancer and metastasis. Cancer Metastasis Rev 2015;34:319-31.

11. De Visser KE, Eichten A, Coussens LM. Paradoxical roles of the immune system during cancer development. Nat Rev Cancer2006;6:24-37.

12. Landskron G, De la Fuente M, Thuwajit $P$, et al. Chronic inflammation and cytokines in the tumor microenvironment. J Immunol Res 2014;2014.

13. Goldberg JL, Sondel PM. Enhancing cancer 
immunotherapy via activation of innate immunity. Semin Oncol 2015;42:562-72.

14. Conway EM, Pikor LA, Kung SH, et al. Macrophages, inflammation, and lung cancer. Am J Respir Crit Care Med 2016;193:116-30.

15. Saqib U, Sarkar S, Suk K, et al. Phytochemicals as modulators of M1-M2 macrophages in inflammation. Oncotarget 2018;9:17937-50.

16. Quatromoni JG, Eruslanov E. Tumor-associated macrophages: function, phenotype, and link to prognosis in human lung cancer. Am J Transl Res2012;4:376-89.

17. Orekhov AN, Orekhova VA, Nikiforov NG, et al. Monocyte differentiation and macrophage polarization. Vessel Plus 2019;3:10.

18. Ley K. M1 means kill; M2 means heal. J Immunol2017;199:2191-3.

19. Nathan C. Role of iNOS in human host defense. Science 2006;312:1874-5.

20. Mitsi E, Kamng'ona R, Rylance J, et al. Human alveolar macrophages predominately express combined classical M1 and M2 surface markers in steady state. Respir Res 2018;19:66.

21. Wang LX, Zhang SX, Wu HJ, et al. M2b macrophage polarization and its roles in diseases. J Leukoc Biol 2019;106:345-58.

22. Becker M, Müller CB, De Bastiani MA, et al. The prognostic impact of tumor-associated macrophages and intra-tumoral apoptosis in non-small cell lung cancer. Histol Histopathol 2014;29:21-31.

23. Wang R, Zhang J, Chen S, et al. Tumor-associated macrophages provide a suitable microenvironment for non-small lung cancer invasion and progression. Lung Cancer 2011;74:188-96.

24. Ryder M, Ghossein RA, Ricarte-Filho JC, et al. Increased density of tumor-associated macrophages is associated with decreased survival in advanced thyroid cancer. Endocr Relat Cancer 2008;15:1069-74.

25. Poh AR, Ernst M. Targeting macrophages in cancer: from bench to bedside. Front Oncol 2018;8:49.

26. Ren F, Fan M, Mei J, et al. Interferon- $\gamma$ and celecoxib inhibit lung-tumor growth through modulating M2/M1 macrophage ratio in the tumor microenvironment. Drug Des Devel Ther 2014;8:1527-38.

27. Yang L, Zhang Y. Tumor-associated macrophages, potential targets for cancer treatment. Biomark Res 2017;5:25.

28. Lewis CE, Pollard JW. Distinct role of macrophages in different tumor microenvironments. Cancer Res
2006;66:605-12.

29. Astekar M, Metgud R, Sharma A, et al. Hidden keys in stroma: Unlocking the tumor progression. J Oral Maxillofac Pathol 2013;17:82-8.

30. Domagala-Kulawik J. The relevance of bronchoalveolar lavage fluid analysis for lung cancer patients. Expert Rev Respir Med 2020;14:329-37.

31. Thomassen MJ, Ahmad M, Barna BP, et al. Induction of cytokine messenger RNA and secretion in alveolar macrophages and blood monocytes from patients with lung cancer receiving granulocyte-macrophage colonystimulating factor therapy. Cancer Res 1991;51:857-62.

32. Pouniotis DS, Plebanski M, Apostolopoulos V, et al. Alveolar macrophage function is altered in patients with lung cancer. Clin Exp Immunol 2006;143:363-72.

33. Dabrowska M, Grubek-Jaworska H, Hoser G, et al. Effect of IFN-gamma stimulation on expression of intercellular adhesion molecule-1 (ICAM-1) on alveolar macrophages in patients with non-small cell lung cancer. J Interferon Cytokine Res 2006;26:190-5.

34. Sumitomo R, Hirai T, Fujita M, et al. M2 tumor-associated macrophages promote tumor progression in non-small-cell lung cancer. Exp Ther Med 2019;18:4490-8.

35. Lopez-Gonzalez JS, Avila-Moreno F, Prado-Garcia H, et al. Lung carcinomas decrease the number of monocytes/ macrophages (CD14+ cells) that produce TNF- $\alpha$. Clin Immunol 2007;122:323-9.

36. Hu JM, Liu K, Liu JH, et al. The increased number of tumor-associated macrophage is associated with overexpression of VEGF-C, plays an important role in Kazakh ESCC invasion and metastasis. Exp Mol Pathol 2017;102:15-21.

37. Liu YC, Zou XB, Chai YF, et al. Macrophage polarization in inflammatory diseases. Int J Biol Sci 2014;10:520-9.

38. Solinas G, Germano G, Mantovani A, et al. Tumorassociated macrophages (TAM) as major players of the cancer-related inflammation. J Leukoc Biol 2009;86:1065-73.

39. Frezzetti D, Gallo M, Maiello MR, et al. VEGF as a potential target in lung cancer. Expert Opin Ther Targets 2017;21:959-66.

40. Chen JJ, Yao PL, Yuan A, et al. Up-regulation of tumor interleukin-8 expression by infiltrating macrophages: its correlation with tumor angiogenesis and patient survival in non-small cell lung cancer. Clin Cancer Res 2003;9:729-37.

41. Redente EF, Dwyer-Nield LD, Merrick DT, et al. Tumor progression stage and anatomical site regulate 
tumor-associated macrophage and bone marrow-derived monocyte polarization. Am J Pathol 2010;176:2972-85.

42. Ma J, Liu L, Che G, et al. The M1 form of tumorassociated macrophages in non-small cell lung cancer is positively associated with survival time. BMC Cancer 2010;10:112.

43. Yuan A, Hsiao YJ, Chen HY, et al. Opposite effects of M1 and M2 macrophage subtypes on lung cancer progression. Sci Rep 2015;5:14273.

44. Zeni E, Mazzetti L, Miotto D, et al. Macrophage expression of interleukin-10 is a prognostic factor in nonsmall cell lung cancer. Eur Respir J 2007;30:627-32.

45. Wagner S, Czub S, Greif M, et al. Microglial/macrophage expression of interleukin 10 in human glioblastomas. Int J Cancer 1999;82:12-6.

46. Wang R, Lu M, Chen H, et al. Increased IL-10 mRNA expression in tumor-associated macrophage correlated with late stage of lung cancer. J Exp Clin Cancer Res 2011;30:62.

47. Vahl JM, Friedrich J, Mittler S, et al. Interleukin-10regulated tumour tolerance in non-small cell lung cancer. Br J Cancer 2017;117:1644-55.

48. Zeng L, O'Connor C, Zhang J, et al. IL-10 promotes resistance to apoptosis and metastatic potential in lung tumor cell lines. Cytokine 2010;49:294-302.

49. Mei J, Xiao Z, Guo C, et al. Prognostic impact of tumorassociated macrophage infiltration in non-small cell lung cancer: A systemic review and meta-analysis. Oncotarget 2016;7:34217-28.

50. Welsh TJ, Green RH, Richardson D, et al. Macrophage and mast-cell invasion of tumor cell islets confers a marked survival advantage in non-small-cell lung cancer. J Clin Oncol 2005;23:8959-67.

51. Zhang QW, Liu L, Gong CY, et al. Prognostic significance of tumor-associated macrophages in solid tumor: a metaanalysis of the literature. PLoS One 2012;7:e50946.

52. O'Callaghan DS, O'Donnell D, O'Connell F, et al. The role of inflammation in the pathogenesis of non-small cell lung cancer. J Thorac Oncol 2010;5:2024-36.

53. Jung KY, Cho SW, Kim YA, et al. Cancers with higher density of tumor-associated macrophages were associated with poor survival rates. J Pathol Transl Med 2015;49:318-24.

54. Zhang B, Yao G, Zhang Y, et al. M2-polarized tumorassociated macrophages are associated with poor prognoses resulting from accelerated lymphangiogenesis in lung adenocarcinoma. Clinics (Sao Paulo) 2011;66:1879-86.

55. Wu P, Wu D, Zhao L, et al. Inverse role of distinct subsets and distribution of macrophage in lung cancer prognosis: a meta-analysis. Oncotarget 2016;7:40451-60.

56. Cao L, Che X, Qiu X, et al. M2 macrophage infiltration into tumor islets leads to poor prognosis in non-small-cell lung cancer. Cancer Manag Res 2019;11:6125-38.

57. Dai F, Liu L, Che G, et al. The number and microlocalization of tumor-associated immune cells are associated with patient's survival time in non-small cell lung cancer. BMC Cancer 2010;10:220.

58. Ruffell B, Coussens LM. Macrophages and therapeutic resistance in cancer. Cancer Cell 2015;27:462-72.

59. Rakaee M, Busund LTR, Jamaly S, et al. Prognostic Value of Macrophage Phenotypes in Resectable Non-Small Cell Lung Cancer Assessed by Multiplex Immunohistochemistry. Neoplasia 2019;21:282-93.

60. Liao X, Sharma N, Kapadia F, et al. Krüppel-like factor 4 regulates macrophage polarization. J Clin Invest 2011;121:2736-49.

61. Porta C, Rimoldi M, Raes G, et al. Tolerance and M2 (alternative) macrophage polarization are related processes orchestrated by p50 nuclear factor $\kappa$ B. Proc Natl Acad Sci U S A 2009;106:14978-83.

62. Davis MJ, Tsang TM, Qiu Y, et al. Macrophage M1/M2 polarization dynamically adapts to changes in cytokine microenvironments in Cryptococcus neoformans infection. MBio 2013;4:e00264-13.

63. Mantovani A, Sozzani S, Locati M, et al. Macrophage polarization: tumor-associated macrophages as a paradigm for polarized M2 mononuclear phagocytes. Trends Immunol 2002;23:549-55.

64. Shapouri-Moghaddam A, Mohammadian S, Vazini H, et al. Macrophage plasticity, polarization, and function in health and disease. J Cell Physiol 2018;233:6425-40.

65. Ma B, Yang Y, Li Z, et al. Modular bioinformatics analysis demonstrates that a Tolllike receptor signaling pathway is involved in the regulation of macrophage polarization. Mol Med Rep 2018;18:4313-20.

66. Chanmee T, Ontong P, Konno K, et al. Tumorassociated macrophages as major players in the tumor microenvironment. Cancers 2014;6:1670-90.

67. Haabeth OAW, Lorvik KB, Hammarström C, et al. Inflammation driven by tumour-specific Th1 cells protects against B-cell cancer. Nat Commun 2011;2:240.

68. Pace JL, Russell SW, Schreiber RD, et al. Macrophage activation: priming activity from a T-cell hybridoma is attributable to interferon-gamma. Proc Natl Acad Sci U S A 1983;80:3782-6.

69. Ni L, Lu J. Interferon gamma in cancer immunotherapy. 
Cancer Med 2018;7:4509-16.

70. D'Andrea A, Rengaraju M, Valiante NM, et al. Production of natural killer cell stimulatory factor (interleukin 12) by peripheral blood mononuclear cells. J Exp Med 1992;176:1387-98.

71. Kobayashi M, Fitz L, Ryan M, et al. Identification and purification of natural killer cell stimulatory factor (NKSF), a cytokine with multiple biologic effects on human lymphocytes. J Exp Med 1989;170:827-45.

72. Yoshida A, Koide Y, Uchijima M, et al. IFN- $\gamma$ induces IL12 mRNA expression by a murine macrophage cell line, J774. Biochem Biophys Res Commun 1994;198:857-61.

73. Yu X, Wu B, Ma T, et al. Overexpression of IL-12 reverses the phenotype and function of M2 macrophages to M1 macrophages. Int J Clin Exp Pathol 2016;9:8963-72.

74. Wang F, Xu J, Zhu Q, et al. Downregulation of IFNG in CD4+ T cells in lung cancer through hypermethylation: a possible mechanism of tumor-induced immunosuppression. PLoS One 2013;8:e79064.

75. Redente EF, Dwyer-Nield LD, Barrett BS, et al. Lung tumor growth is stimulated in IFN- $\gamma-/-$ mice and inhibited in IL-4R $\alpha-/-$ mice. Anticancer Res 2009;29:5095-101.

76. Song M, Ping Y, Zhang K, et al. Low-Dose IFN $\gamma$ Induces Tumor Cell Stemness in Tumor Microenvironment of Non-Small Cell Lung Cancer. Cancer Res 2019;79:3737-48.

77. Eifuku R, Yoshimatsu T, Yoshino I, et al. Heterogeneous response patterns of alveolar macrophages from patients with lung cancer by stimulation with interferon- $\gamma$. Jpn J Clin Oncol 2000;30:295-300.

78. Müller E, Christopoulos PF, Halder S, et al. Tolllike receptor ligands and interferon- $\gamma$ synergize for induction of antitumor M1 macrophages. Front Immunol 2017;8:1383.

79. Matanić D, Beg-Zec Z, Stojanović D, et al. Cytokines in patients with lung cancer. Scand J Immunol 2003;57:173-8.

80. Pine SR, Mechanic LE, Enewold L, et al. Increased levels of circulating interleukin 6, interleukin 8, C-reactive protein, and risk of lung cancer. J Natl Cancer Inst 2011;103:1112-22.

81. Song XY, Zhou SJ, Xiao N, et al. Research on the relationship between serum levels of inflammatory cytokines and non-small cell lung cancer. Asian Pac J Cancer Prev 2013;14:4765-8.

82. Mauer J, Chaurasia B, Goldau J, et al. Signaling by IL-6 promotes alternative activation of macrophages to limit endotoxemia and obesity-associated resistance to insulin.
Nat Immunol 2014;15:423-30.

83. Bhattacharjee A, Xu B, Frank DA, et al. Monocyte 15-Lipoxygenase Expression Is Regulated by a Novel Cytosolic Signaling Complex with Protein Kinase C $\delta$ and Tyrosine-Phosphorylated Stat3. J Immunol 2006;177:3771-81.

84. Iriki T, Ohnishi K, Fujiwara Y, et al. The cell-cell interaction between tumor-associated macrophages and small cell lung cancer cells is involved in tumor progression via STAT3 activation. Lung Cancer 2017;106:22-32.

85. Weng YS, Tseng HY, Chen YA, et al. MCT-1/miR-34a/ IL-6/IL-6R signaling axis promotes EMT progression, cancer stemness and M2 macrophage polarization in triple-negative breast cancer. Mol Cancer 2019;18:42.

86. Song L, Smith MA, Doshi P, et al. Antitumor efficacy of the anti-interleukin-6 (IL-6) antibody siltuximab in mouse xenograft models of lung cancer. J Thorac Oncol 2014;9:974-82.

87. Caetano MS, Zhang H, Cumpian AM, et al. IL6 blockade reprograms the lung tumor microenvironment to limit the development and progression of K-ras-mutant lung cancer. Cancer Res 2016;76:3189-99.

88. Dijkgraaf EM, Santegoets SJ, Reyners AK, et al. A phase I trial combining carboplatin/doxorubicin with tocilizumab, an anti-IL-6R monoclonal antibody, and interferon- $\alpha 2 \mathrm{~b}$ in patients with recurrent epithelial ovarian cancer. Ann Oncol 2015;26:2141-9.

89. Brighton TA, Khot A, Harrison SJ, et al. Randomized, Double-Blind, Placebo-Controlled, Multicenter Study of Siltuximab in High-Risk Smoldering Multiple Myeloma. Clin Cancer Res 2019;25:3772-5.

90. Bayliss TJ, Smith JT, Schuster M, et al. A humanized antiIL-6 antibody (ALD518) in non-small cell lung cancer. Expert Opin Biol Ther 2011;11:1663-8.

91. Fleetwood AJ, Lawrence T, Hamilton JA, et al. Granulocyte-macrophage colony-stimulating factor (CSF) and macrophage CSF-dependent macrophage phenotypes display differences in cytokine profiles and transcription factor activities: implications for CSF blockade in inflammation. J Immunol 2007;178:5245-52.

92. Stanley ER, Chitu V. CSF-1 receptor signaling in myeloid cells. Cold Spring Harb Perspect Biol 2014;6:a021857.

93. Wang N, Liang H, Zen K. Molecular mechanisms that influence the macrophage M1-M2 polarization balance. Front Immunol 2014;5:614.

94. Guidez F, Li AC, Horvai A, et al. Differential utilization of Ras signaling pathways by macrophage colony-stimulating factor (CSF) and granulocyte-macrophage CSF receptors 
during macrophage differentiation. Mol Cell Biol 1998;18:3851-61.

95. Lacey DC, Achuthan A, Fleetwood AJ, et al. Defining GM-CSF- and Macrophage-CSF-Dependent Macrophage Responses by In Vitro Models. J Immunol 2012;188:5752-65.

96. Coelho AL, Gomes MP, Catarino RJ, et al. CSF-1 and Ang-2 serum levels_-prognostic and diagnostic partners in non-small cell lung cancer. ESMO Open 2018;3:e000349.

97. Bahar B, Cayci B, Coskun U, et al. Granulocyte colony stimulating factor (G-CSF) and macrophage colony stimulating factor (M-CSF) as potential tumor markers in non small cell lung cancer diagnosis. Asian Pac J Cancer Prev 2010;11:709-12.

98. Inamura K, Shigematsu Y, Ninomiya H, et al. CSF1Rexpressing tumor-associated macrophages, smoking and survival in lung adenocarcinoma: analyses using quantitative phosphor-integrated dot staining. Cancers 2018;10:252.

99. Yao Z, Zhang J, Zhang B, et al. Imatinib prevents lung cancer metastasis by inhibiting M2-like polarization of macrophages. Pharmacol Res 2018;133:121-31.

100.Almatroodi SA, McDonald CF, Pouniotis DS. Alveolar macrophage polarisation in lung cancer. Lung Cancer Int 2014;2014:721087.

101. Cannarile MA, Weisser M, Jacob W, et al. Colonystimulating factor 1 receptor (CSF1R) inhibitors in cancer therapy. J Immunother Cancer 2017;5:53.

102.Hu-Lieskovan S, Patnaik A, Eisenberg P, et al. Phase $1 / 2$ a study of double immune suppression blockade by combining a CSF1R inhibitor (pexidartinib/PLX3397) with an anti PD-1 antibody (pembrolizumab) to treat advanced melanoma and other solid tumors. Ann Oncol 2015;26:viii5.

103. Ullah MO, Sweet MJ, Mansell A, et al. TRIF-dependent TLR signaling, its functions in host defense and inflammation, and its potential as a therapeutic target. J Leukoc Biol 2016;100:27-45.

104.Lee M, Park CS, Lee YR, et al. Resiquimod, a TLR7/8 agonist, promotes differentiation of myeloid-derived suppressor cells into macrophages and dendritic cells. Arch Pharm Res 2014;37:1234-40.

105. Geeraerts X, Bolli E, Fendt SM, et al. Macrophage metabolism as therapeutic target for cancer, atherosclerosis, and obesity. Front Immunol 2017;8:289.

106. West AP, Brodsky IE, Rahner C, et al. TLR signalling augments macrophage bactericidal activity through mitochondrial ROS. Nature 2011;472:476-80.
107.Zhang YB, He FL, Fang M, et al. Increased expression of Toll-like receptors 4 and 9 in human lung cancer. Mol Biol Rep 2009;36:1475-81.

108.Zhou H, Chen JH, Hu J, et al. High expression of Tolllike receptor 5 correlates with better prognosis in nonsmall-cell lung cancer: an anti-tumor effect of TLR5 signaling in non-small cell lung cancer. J Cancer Res Clin Oncol 2014;140:633-43.

109. Li D, Jin Y, Sun Y, et al. Knockdown of toll-like receptor 4 inhibits human NSCLC cancer cell growth and inflammatory cytokine secretion in vitro and in vivo. Int $\mathrm{J}$ Oncol 2014;45:813-21.

110. Chatterjee S, Crozet L, Damotte D, et al. TLR7 promotes tumor progression, chemotherapy resistance, and poor clinical outcomes in non-small cell lung cancer. Cancer Res 2014;74:5008-18.

111.van Dalen FJ, van Stevendaal M, Fennemann FL, et al. Molecular Repolarisation of Tumour-Associated Macrophages. Molecules 2018;24:9.

112.Lee CH, Wu CL, Shiau AL. Toll-like receptor 4 signaling promotes tumor growth. J Immunother 2010;33:73-82.

113. Gao Y, Chen L, Hou M, et al. TLR2 directing PDL2 expression inhibit T cells response in Schistosoma japonicum infection. PLoS One 2013;8:e82480.

114.Kim S, Takahashi H, Lin WW, et al. Carcinoma-produced factors activate myeloid cells through TLR2 to stimulate metastasis. Nature 2009;457:102-6.

115. Keller R, Fischer W, Keist R, et al. Macrophage response to bacteria: induction of marked secretory and cellular activities by lipoteichoic acids. Infect Immun 1992;60:3664-72.

116. Ke X, Wu M, Lou J, et al. Activation of Toll-like receptors signaling in non-small cell lung cancer cell line induced by tumor-associated macrophages. Chin J Cancer Res 2015;27:181-9.

117. Shirota Y, Shirota H, Klinman DM. Intratumoral injection of $\mathrm{CpG}$ oligonucleotides induces the differentiation and reduces the immunosuppressive activity of myeloidderived suppressor cells. J Immunol 2012;188:1592-9.

118. Smale ST. Selective transcription in response to an inflammatory stimulus. Cell 2010;140:833-44.

119.Zhou D, Huang C, Lin Z, et al. Macrophage polarization and function with emphasis on the evolving roles of coordinated regulation of cellular signaling pathways. Cell Signal 2014;26:192-7.

120. Bonizzi G, Karin M. The two NF- $\kappa$ B activation pathways and their role in innate and adaptive immunity. Trends Immunol 2004;25:280-8. 
121. Yang L, Wang F, Wang L, et al. CD163+ tumor-associated macrophage is a prognostic biomarker and is associated with therapeutic effect on malignant pleural effusion of lung cancer patients. Oncotarget 2015;6:10592-603.

122.Zhao XM, Pan SY, Huang QL, et al. PA-MSHA in combination with EGFR tyrosine kinase inhibitor: A new strategy to overcome the drug resistance of non-small cell lung cancer cells. Oncotarget 2016;7:49384-96.

123. Monk BJ, Brady MF, Aghajanian C, et al. A phase 2, randomized, double-blind, placebo- controlled study of chemo-immunotherapy combination using motolimod with pegylated liposomal doxorubicin in recurrent or persistent ovarian cancer: a Gynecologic Oncology Group partners study. Ann Oncol 2017;28:996-1004.

124. Ruzsa A, Sen M, Evans M, et al. Phase 2, open-label, 1:1 randomized controlled trial exploring the efficacy of EMD 1201081 in combination with cetuximab in secondline cetuximab-naïve patients with recurrent or metastatic squamous cell carcinoma of the head and neck (R/M SCCHN). Invest New Drugs 2014;32:1278-84.

125. Smith DA, Conkling P, Richards DA, et al. Antitumor activity and safety of combination therapy with the Toll-like receptor 9 agonist IMO-2055, erlotinib, and bevacizumab in advanced or metastatic nonsmall cell lung cancer patients who have progressed following chemotherapy. Cancer Immunol Immunother 2014;63:787-96.

126. He J, Hu Y, Hu M, et al. Development of PD-1/PDL1 Pathway in Tumor Immune Microenvironment and Treatment for Non-Small Cell Lung Cancer. Sci Rep 2015;5:13110.

127. Cassetta L, Kitamura T. Targeting Tumor-Associated Macrophages as a Potential Strategy to Enhance the Response to Immune Checkpoint Inhibitors. Front Cell Dev Biol 2018;6:38.

128.Gordon SR, Maute RL, Dulken BW, et al. PD-1 expression by tumour-associated macrophages inhibits phagocytosis and tumour immunity. Nature 2017;545:495-9.

129.Cho HY, Lee SW, Seo SK, et al. Interferon-sensitive response element (ISRE) is mainly responsible for IFN-alpha-induced upregulation of programmed death-1 (PD-1) in macrophages. Biochim Biophys Acta 2008;1779:811-9.

130.Liu Y, Zugazagoitia J, Ahmed FS, et al. Immune Cell PD-L1 Colocalizes with Macrophages and Is Associated with Outcome in PD-1 Pathway Blockade Therapy. Clin Cancer Res 2020;26:970-7.
131. Hartley GP, Chow L, Ammons DT, et al. Programmed Cell Death Ligand 1 (PD-L1) Signaling Regulates Macrophage Proliferation and Activation. Cancer Immunol Res 2018;6:1260-73.

132. Singhal S, Stadanlick J, Annunziata MJ, et al. Human tumor-associated monocytes/macrophages and their regulation of $\mathrm{T}$ cell responses in early-stage lung cancer. Sci Transl Med 2019;11:eaat1500.

133. Palsson-McDermott EM, Dyck L, Zasłona Z, et al. Pyruvate Kinase M2 Is Required for the Expression of the Immune Checkpoint PD-L1 in Immune Cells and Tumors. Front Immunol 2017;8:1300.

134.Zhang Y, Du W, Chen Z, et al. Upregulation of PD-L1 by SPP1 mediates macrophage polarization and facilitates immune escape in lung adenocarcinoma. Exp Cell Res 2017;359:449-57.

135. Sepesi B, Cuentas EP, Canales JR, et al. Programmed Death Cell Ligand 1 (PD-L1) Is Associated With Survival in Stage I Non-Small Cell Lung Cancer. Semin Thorac Cardiovasc Surg 2017;29:408-15.

136. Herbst RS, Baas P, Kim DW, et al. Pembrolizumab versus docetaxel for previously treated, PD-L1-positive, advanced non-small-cell lung cancer (KEYNOTE-010): a randomised controlled trial. Lancet 2016;387:1540-50.

137. Fehrenbacher L, Spira A, Ballinger M, et al. Atezolizumab versus docetaxel for patients with previously treated non-small-cell lung cancer (POPLAR): a multicentre, open-label, phase 2 randomised controlled trial. Lancet 2016;387:1837-46.

138. Borghaei H, Paz-Ares L, Horn L, et al. Nivolumab versus Docetaxel in Advanced Nonsquamous Non-Small-Cell Lung Cancer. N Engl J Med 2015;373:1627-39.

139. Brahmer J, Reckamp KL, Baas P, et al. Nivolumab versus Docetaxel in Advanced Squamous-Cell Non-Small-Cell Lung Cancer. N Engl J Med 2015;373:123-35.

140. Grimson A, Farh KKH, Johnston WK, et al. MicroRNA targeting specificity in mammals: determinants beyond seed pairing. Mol Cell 2007;27:91-105.

141. Bartel DP, Chen CZ. Micromanagers of gene expression: the potentially widespread influence of metazoan microRNAs. Nat Rev Genet 2004;5:396-400.

142.Essandoh K, Li Y, Huo J, et al. MiRNA-mediated macrophage polarization and its potential role in the regulation of inflammatory response. Shock 2016;46:122-31.

143.Wu XQ, Dai Y, Yang Y, et al. Emerging role of micro RNA $\mathrm{s}$ in regulating macrophage activation and polarization in immune response and inflammation. Immunology 
2016;148:237-48.

144. Graff JW, Dickson AM, Clay G, et al. Identifying functional microRNAs in macrophages with polarized phenotypes. J Biol Chem 2012;287:21816-25.

145. Chaudhuri AA, So AYL, Sinha N, et al. MicroRNA$125 \mathrm{~b}$ potentiates macrophage activation. $\mathrm{J}$ Immunol 2011;187:5062-8.

146.Zhong Y, Yi C. MicroRNA-720 suppresses M2 macrophage polarization by targeting GATA3. Biosci Rep 2016;36:e00363.

147. Martinez-Nunez RT, Louafi F, Sanchez-Elsner T. The interleukin 13 (IL-13) pathway in human macrophages is modulated by microRNA-155 via direct targeting of interleukin 13 receptor $\alpha 1$ (IL13R $\alpha 1$ ). J Biol Chem 2011;286:1786-94.

148.Zhang P, Wang H, Luo X, et al. MicroRNA-155 inhibits polarization of macrophages to M2-type and suppresses choroidal neovascularization. Inflammation 2018;41:143-53.

149. O'Connell RM, Rao DS, Chaudhuri AA, et al. Sustained expression of microRNA-155 in hematopoietic stem cells causes a myeloproliferative disorder. J Exp Med 2008;205:585-94.

150. Yao F, Yu Y, Feng L, et al. Adipogenic miR-27a in adipose tissue upregulates macrophage activation via inhibiting PPAR $\gamma$ of insulin resistance induced by high-fat dietassociated obesity. Exp Cell Res 2017;355:105-12.

151.Jennewein C, von Knethen A, Schmid T, et al. MicroRNA$27 \mathrm{~b}$ contributes to lipopolysaccharide-mediated peroxisome proliferator-activated receptor $\gamma(\operatorname{PPAR} \gamma)$ mRNA destabilization. J Biol Chem 2010;285:11846-53.

152.Zhao JL, Huang F, He F, et al. Forced activation of Notch in macrophages represses tumor growth by upregulating miR-125a and disabling tumor-associated macrophages. Cancer Res 2016;76:1403-15.

153. Wang Z, Brandt S, Medeiros A, et al. MicroRNA 21 is a homeostatic regulator of macrophage polarization and prevents prostaglandin E2-mediated M2 generation. PLoS One 2015;10:e0115855.

154. Ying H, Kang Y, Zhang H, et al. MiR-127 modulates macrophage polarization and promotes lung inflammation and injury by activating the JNK pathway. J Immunol 2015;194:1239-51.

155. Zhuang G, Meng C, Guo X, et al. A novel regulator of macrophage activation: miR-223 in obesity-associated adipose tissue inflammation. Circulation 2012;125:2892-903.

156. Rasheed Z, Al-Shobaili HA, Rasheed N, et al. MicroRNA$26 a-5 p$ regulates the expression of inducible nitric oxide synthase via activation of $\mathrm{NF}-\kappa \mathrm{B}$ pathway in human osteoarthritis chondrocytes. Arch Biochem Biophys 2016;594:61-7.

157. Thulin P, Wei T, Werngren O, et al. MicroRNA-9 regulates the expression of peroxisome proliferatoractivated receptor $\delta$ in human monocytes during the inflammatory response. Int J Mol Med 2013;31:1003-10.

158. Lin L, Lin H, Wang L, et al. miR-130a regulates macrophage polarization and is associated with non-small cell lung cancer. Oncol Rep 2015;34:3088-96.

159.Zhang M, Zhou Z, Wang J, et al. MiR-130b promotes obesity associated adipose tissue inflammation and insulin resistance in diabetes mice through alleviating M2 macrophage polarization via repression of PPAR $-\gamma$. Immunol Lett 2016;180:1-8.

160. Banerjee S, Cui H, Xie N, et al. miR-125a-5p regulates differential activation of macrophages and inflammation. J Biol Chem 2013;288:35428-36.

161.Jiang P, Liu R, Zheng Y, et al. MiR-34a inhibits lipopolysaccharide-induced inflammatory response through targeting Notch1 in murine macrophages. Exp Cell Res 2012;318:1175-84.

162. Cobos Jiménez V, Bradley EJ, Willemsen AM, et al. Nextgeneration sequencing of microRNAs uncovers expression signatures in polarized macrophages. Physiol Genomics 2014;46:91-103.

163.Li D, Duan M, Feng Y, et al. MiR-146a modulates macrophage polarization in systemic juvenile idiopathic arthritis by targeting INHBA. Mol Immunol 2016;77:205-12.

164.Niu X, Schulert G. Functional Regulation of Macrophage Phenotypes by MicroRNAs in Inflammatory Arthritis. Front Immunol 2019;10:2217.

165. Taganov KD, Boldin MP, Chang KJ, et al. NF-кBdependent induction of microRNA miR-146, an inhibitor targeted to signaling proteins of innate immune responses. Proc Natl Acad Sci U S A 2006;103:12481-6.

166. Chen L, Dai YM, Ji CB, et al. MiR-146b is a regulator of human visceral preadipocyte proliferation and differentiation and its expression is altered in human obesity. Mol Cell Endocrinol 2014;393:65-74.

167. Chen Q, Wang H, Liu Y, et al. Inducible microRNA-223 down-regulation promotes TLR-triggered IL-6 and IL$1 \beta$ production in macrophages by targeting STAT3. PLoS One 2012;7:e42971.

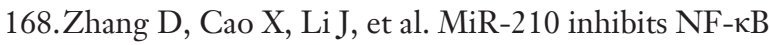
signaling pathway by targeting DR6 in osteoarthritis. Sci Rep 2015;5:12775. 
169. Qi J, Qiao Y, Wang P, et al. microRNA-210 negatively regulates LPS-induced production of proinflammatory cytokines by targeting NF- $\kappa \mathrm{B} 1$ in murine macrophages. FEBS Lett 2012;586:1201-7.

170. Ouimet M, Ediriweera HN, Gundra UM, et al. MicroRNA-33-dependent regulation of macrophage metabolism directs immune cell polarization in atherosclerosis. J Clin Invest 2015;125:4334-48.

171.Ying X, Wu Q, Wu X, et al. Epithelial ovarian cancersecreted exosomal miR-222-3p induces polarization of tumor-associated macrophages. Oncotarget 2016;7:43076-87.

172. Curtale G. MiRNAs at the crossroads between innate immunity and cancer: focus on macrophages. Cells 2018;7:12.

173.Liu F, Li Y, Jiang R, et al. miR-132 inhibits lipopolysaccharide-induced inflammation in alveolar macrophages by the cholinergic anti-inflammatory pathway. Exp Lung Res 2015;41:261-9.

174. Yu A, Zhang T, Duan H, et al. MiR-124 contributes to M2 polarization of microglia and confers brain inflammatory protection via the $\mathrm{C} / \mathrm{EBP}-\alpha$ pathway in intracerebral hemorrhage. Immunol Lett 2017;182:1-11.

175.Sun Y, Li Q, Gui H, et al. MicroRNA-124 mediates the cholinergic anti-inflammatory action through inhibiting the production of pro-inflammatory cytokines. Cell Res 2013;23:1270-83.

176. Ma F, Liu X, Li D, et al. MicroRNA-4661 upregulates IL-10 expression in TLR-triggered macrophages by antagonizing RNA-binding protein tristetraprolinmediated IL-10 mRNA degradation. J Immunol 2010;184:6053-9.

177.Ganta VC, Choi MH, Kutateladze A, et al. A microRNA93-interferon regulatory factor-9immunoresponsive Gene-1-itaconic acid pathway modulates M2-like macrophage polarization to revascularize ischemic muscle. Circulation 2017;135:2403-25.

178. Caescu CI, Guo X, Tesfa L, et al. Colony stimulating factor-1 receptor signaling networks inhibit mouse macrophage inflammatory responses by induction of microRNA-21. Blood 2015;125:e1-e13.

179. Bi J, Zeng X, Zhao L, et al. miR-181a induces macrophage polarized to M2 phenotype and promotes M2 macrophagemediated tumor cell metastasis by targeting KLF6 and C/ EBP $\alpha$. Mol Ther Nucleic Acids 2016;5:e368.

180. Fortunato O, Borzi C, Milione M, et al. Circulating mir320a promotes immunosuppressive macrophages M2 phenotype associated with lung cancer risk. Int J Cancer 2019;144:2746-61.

181. Hirono T, Jingushi K, Nagata T, et al. MicroRNA-130b functions as an oncomiRNA in non-small cell lung cancer by targeting tissue inhibitor of metalloproteinase-2. Sci Rep 2019;9:6956.

182.Xu TP, Zhu CH, Zhang J, et al. MicroRNA-155 expression has prognostic value in patients with non-small cell lung cancer and digestive system carcinomas. Asian Pac J Cancer Prev 2013;14:7085-90.

183. Han L, Lam EWF, Sun Y. Extracellular vesicles in the tumor microenvironment: old stories, but new tales. Mol Cancer 2019;18:59.

184. Hsu YL, Hung JY, Chang WA, et al. Hypoxic LungCancer-Derived Extracellular Vesicle MicroRNA-103a Increases the Oncogenic Effects of Macrophages by Targeting PTEN. Mol Ther 2018;26:568-81.

185. Wang D, Wang X, Si M, et al. Exosome-encapsulated miRNAs contribute to CXCL12/CXCR4-induced liver metastasis of colorectal cancer by enhancing M2 polarization of macrophages. Cancer Lett 2020;474:36-52.

186. Wang X, Luo G, Zhang K, et al. Hypoxic TumorDerived Exosomal miR-301a Mediates M2 Macrophage Polarization via PTEN/PI3K $\gamma$ to Promote Pancreatic Cancer Metastasis. Cancer Res 2018;78:4586-98.

187. Chen X, Zhou J, Li X, et al. Exosomes derived from hypoxic epithelial ovarian cancer cells deliver microRNAs to macrophages and elicit a tumor-promoted phenotype. Cancer Lett 2018;435:80-91.

188.Ma R, Ji T, Chen D, et al. Tumor cell-derived microparticles polarize M2 tumor-associated macrophages for tumor progression. Oncoimmunology 2016;5:e1118599.

189. Shinohara H, Kuranaga Y, Kumazaki M, et al. Regulated Polarization of Tumor-Associated Macrophages by miR145 via Colorectal Cancer-Derived Extracellular Vesicles. J Immunol 2017;199:1505-15.

190. Chen J, Sun W, Zhang H, et al. Macrophages reprogrammed by lung cancer microparticles promote tumor development via release of IL-1 $\beta$. Cell Mol Immunol 2020;17:1233-44.

191.Liang M, Chen X, Wang L, et al. Cancer-derived exosomal TRIM59 regulates macrophage NLRP3 inflammasome activation to promote lung cancer progression. J Exp Clin Cancer Res 2020;39:176.

192.DeNardo DG, Ruffell B. Macrophages as regulators of tumour immunity and immunotherapy. Nat Rev Immunol 2019;19:369-82. 
193.Pienta KJ, Machiels JP, Schrijvers D, et al. Phase 2 study of carlumab (CNTO 888), a human monoclonal antibody against CC-chemokine ligand 2 (CCL2), in metastatic castration-resistant prostate cancer. Invest New Drugs 2013;31:760-8.

194. Sandhu SK, Papadopoulos K, Fong PC, et al. A firstin-human, first-in-class, phase I study of carlumab (CNTO 888), a human monoclonal antibody against CCchemokine ligand 2 in patients with solid tumors. Cancer Chemother Pharmacol 2013;71:1041-50.

195. Selle F, Heudel PE, Hardy-Bessard AC, et al. GINECO Prospective Non-interventional PROSPECTYON Study: Trabectedin Plus Pegylated Liposomal Doxorubicin for Platinum-sensitive Recurrent Ovarian Cancer. Anticancer Res 2020;40:3939-45.

196. Patel S, von Mehren M, Reed DR, et al. Overall survival and histology-specific subgroup analyses from a phase 3 , randomized controlled study of trabectedin or dacarbazine in patients with advanced liposarcoma or leiomyosarcoma. Cancer 2019;125:2610-20.

197. Noel M, O'Reilly EM, Wolpin BM, et al. Phase 1b study of a small molecule antagonist of human chemokine (C-C motif) receptor 2 (PF-04136309) in combination with nabpaclitaxel/gemcitabine in first-line treatment of metastatic pancreatic ductal adenocarcinoma. Invest New Drugs 2020;38:800-11.

198. Wang-Gillam A, Nywening TM, Sanford DE, et al. Phase IB study of FOLFIRINOX plus PF-04136309 in patients with borderline resectable and locally advanced pancreatic adenocarcinoma (PC). J Clin Oncol 2015;33:338.

199. Group SO. S0916, MLN1202 in Treating Patients With Bone Metastases. U.S. National Library of Medicine. 2018. Available online: https://clinicaltrials.gov/ct2/show/ NCT01015560. Accessed 21 January 2021.

200.Autio KA, Klebanoff CA, Schaer D, et al. Phase 1 study of LY3022855, a colony-stimulating factor-1 receptor (CSF$1 \mathrm{R})$ inhibitor, in patients with metastatic breast cancer (MBC) or metastatic castration-resistant prostate cancer (MCRPC). J Clin Oncol 2019;37:2548.

201. Dowlati A, Rugo HS, Harvey RD, et al. A phase I study of LY3022855, a colony-stimulating factor-1 receptor (CSF$1 \mathrm{R}$ ) inhibitor, in patients (pts) with advanced solid tumors. J Clin Oncol 2017;35:2523.

202.Papadopoulos KP, Gluck L, Martin LP, et al. Firstin-Human Study of AMG 820, a Monoclonal AntiColony-Stimulating Factor 1 Receptor Antibody, in Patients with Advanced Solid Tumors. Clin Cancer Res 2017;23:5703-10.
203. Razak AR, Cleary JM, Moreno V, et al. Safety and efficacy of AMG 820, an anti-colony-stimulating factor 1 receptor antibody, in combination with pembrolizumab in adults with advanced solid tumors. J Immunother Cancer 2020;8:e001006.

204. Daiichi Sankyo I. A Combination Clinical Study of PLX3397 and Pembrolizumab To Treat Advanced Melanoma and Other Solid Tumors. U.S. National Library of Medicine. 2020. Available online: https://clinicaltrials. gov/ct2/show/results/NCT02452424. Accessed 21 January 2021.

205. Butowski N, Colman H, De Groot JF, et al. Orally administered colony stimulating factor 1 receptor inhibitor PLX3397 in recurrent glioblastoma: an Ivy Foundation Early Phase Clinical Trials Consortium phase II study. Neuro Oncol 2016;18:557-64.

206. Cassier PA, Garin G, Eberst L, et al. MEDIPLEX: A phase 1 study of durvalumab (D) combined with pexidartinib $(\mathrm{P})$ in patients (pts) with advanced pancreatic ductal adenocarcinoma (PDAC) and colorectal cancer (CRC). J Clin Oncol 2019;37:2579.

207. Gomez-Roca CA, Italiano A, Le Tourneau C, et al. Phase I study of emactuzumab single agent or in combination with paclitaxel in patients with advanced/metastatic solid tumors reveals depletion of immunosuppressive M2-like macrophages. Ann Oncol 2019;30:1381-92.

208. Cohen DJ, Medina B, Du KL, et al. Phase II multiinstitutional study of nivolumab (Nivo), cabiralizumab (Cabira), and stereotactic body radiotherapy (SBRT) for locally advanced unresectable pancreatic cancer (LAUPC). J Clin Oncol 2019;37:TPS4163.

209. Squibb BM. A Study of Cabiralzumab Given by Itself or With Nivolumab in Advanced Cancer or Cancer That Has Spread. U.S. National Library of Medicine. 2020. Available online: https://clinicaltrials.gov/ct2/show/results/ NCT03158272. Accessed 22 January 2021.

210.Lin CC, Gil-Martin M, Bauer TM, et al. Abstract CT171: Phase I study of BLZ945 alone and with spartalizumab (PDR001) in patients (pts) with advanced solid tumors. Cancer Res 2020;80:CT171.

211. O'Hara MH, Messersmith W, Kindler H, et al. Safety and Pharmacokinetics of CXCR4 Peptide Antagonist, LY2510924, in Combination with Durvalumab in Advanced Refractory Solid Tumors. J Pancreat Cancer 2020;6:21-31.

212. Andtbacka RH, Pierce RH, Campbell JS, et al. Abstract 613: X4P-001, an orally bioavailable CXCR4 antagonist, enhances immune cell infiltration and activation in the 
tumor microenvironment of melanoma. Cancer Res 2018;78:613.

213.Johnson P, Challis R, Chowdhury F, et al. Clinical and Biological Effects of an Agonist Anti-CD40 Antibody: A Cancer Res UK Phase I Study. Clin Cancer Res 2015;21:1321-8.

214. Vonderheide RH, Burg JM, Mick R, et al. Phase I study of the CD40 agonist antibody CP-870,893 combined with carboplatin and paclitaxel in patients with advanced solid tumors. Oncoimmunology 2013;2:e23033.

215. Bajor DL, Mick R, Riese MJ, et al. Long-term outcomes of a phase I study of agonist CD40 antibody and CTLA4 blockade in patients with metastatic melanoma. Oncoimmunology 2018; 7:e1468956.

216. Gray JE, Chiappori A, Williams CC, et al. A phase I/ randomized phase II study of GM.CD40L vaccine in combination with CCL21 in patients with advanced lung adenocarcinoma. Cancer Immunol Immunother 2018;67:1853-62.

217.Kluger H, Weiss SA, Olszanski AJ, et al. Abstract CT089: Phase Ib/II of CD40 agonistic antibody APX005M in combination with nivolumab (nivo) in subjects with metastatic melanoma (M) or non-small cell lung cancer (NSCLC). Cancer Res 2019;79:CT089.

218. Adams S, Kozhaya L, Martiniuk F, et al. Topical TLR7 agonist imiquimod can induce immune-mediated rejection of skin metastases in patients with breast cancer. Clin Cancer Res 2012;18:6748-57.

219. de Macedo EM, Carneiro RC, de Lima PP, et al. Imiquimod cream efficacy in the treatment of periocular nodular basal cell carcinoma: a non-randomized trial. BMC Ophthalmol 2015;15:35.

220.Idera Pharmaceuticals I. Dose Escalation Study in Patients With Relapsed or Refractory DLBCL and MyD88 L265P Mutation. U.S. National Library of Medicine. 2017. Available online: https:/clinicaltrials.gov/ct2/show/results/ NCT02252146. Accessed 22 January 2021.

221. Sabado RL, Pavlick A, Gnjatic S, et al. Resiquimod as an immunologic adjuvant for NY-ESO-1 protein vaccination in patients with high-risk melanoma. Cancer Immunol Res 2015;3:278-87.

222. Rook AH, Gelfand JM, Wysocka M, et al. Topical resiquimod can induce disease regression and enhance T-cell effector functions in cutaneous T-cell lymphoma. Blood 2015;126:1452-61.

223. Diab A, Marcondes M, Kotzin B, et al. Phase Ib: Preliminary clinical activity and immune activation for NKTR-262 [TLR 7/8 agonist] plus NKTR-214 [CD122- biased agonist] in patients (pts) with locally advanced or metastatic solid tumors (REVEAL Phase Ib/II Trial). J Clin Oncol 2019;37:26.

224. Research LIfC. Phase 1/2 Study of Motolimod, Doxorubicin, and Durvalumab in Recurrent, PlatinumResistant Ovarian Cancer. U.S. National Library of Medicine. 2019. Available online: https://clinicaltrials.gov/ ct2/show/results/NCT02431559. Accessed 22 January 2021.

225. Dietsch GN, Lu H, Yang Y, et al. Coordinated Activation of Toll-Like Receptor8 (TLR8) and NLRP3 by the TLR8 Agonist, VTX-2337, Ignites Tumoricidal Natural Killer Cell Activity. PLoS One 2016;11:e0148764.

226. Chan E, Kwak EL, Hwang J, et al. Open-label phase 1b study of FOLFIRI plus cetuximab plus IMO-2055 in patients with colorectal cancer who have progressed following chemotherapy for advanced or metastatic disease. Cancer Chemother Pharmacol 2015;75:701-9.

227. Robert Lowsky SU. A Phase I/II Study of Intratumoral Injection of SD-101. U.S. National Library of Medicine. 2019. Available online: https://clinicaltrials.gov/ct2/show/ results/NCT02254772. Accessed 22 January 2021.

228. Ribas A, Medina T, Kummar S, et al. SD-101 in Combination with Pembrolizumab in Advanced Melanoma: Results of a Phase Ib, Multicenter Study. Cancer Discov 2018;8:1250-7.

229. Patel K, Maris MB, Cheson BD, et al. Ongoing, first-inhuman, phase I dose escalation study of the investigational CD47-blocker TTI-622 in patients with advanced relapsed or refractory lymphoma. J Clin Oncol 2020;38:3030.

230.Lim SY, Yuzhalin AE, Gordon-Weeks AN, et al. Targeting the CCL2-CCR2 signaling axis in cancer metastasis. Oncotarget 2016;7:28697-710.

231. Kalbasi A, Komar C, Tooker GM, et al. Tumor-derived CCL2 mediates resistance to radiotherapy in pancreatic ductal adenocarcinoma. Clin Cancer Res 2017;23:137-48.

232.Sanford DE, Belt BA, Panni RZ, et al. Inflammatory monocyte mobilization decreases patient survival in pancreatic cancer: a role for targeting the CCL2/CCR2 axis. Clin Cancer Res 2013;19:3404-15.

233. Fridlender ZG, Kapoor V, Buchlis G, et al. Monocyte chemoattractant protein-1 blockade inhibits lung cancer tumor growth by altering macrophage phenotype and activating CD8+ cells. Am J Respir Cell Mol Biol 2011;44:230-7.

234. Loberg RD, Ying C, Craig M, et al. Targeting CCL2 with systemic delivery of neutralizing antibodies induces prostate cancer tumor regression in vivo. Cancer Res 
2007;67:9417-24.

235.Li X, Yao W, Yuan Y, et al. Targeting of tumourinfiltrating macrophages via CCL2/CCR2 signalling as a therapeutic strategy against hepatocellular carcinoma. Gut 2017;66:157-67.

236.Schmall A, Al-tamari HM, Herold S, et al. Macrophage and cancer cell cross-talk via CCR2 and CX3CR1 is a fundamental mechanism driving lung cancer. Am J Respir Crit Care Med 2015;191:437-47.

237. Mantovani A, Marchesi F, Malesci A, et al. Tumourassociated macrophages as treatment targets in oncology. Nat Rev Clin Oncol 2017;14:399-416.

238. Pyonteck SM, Akkari L, Schuhmacher AJ, et al. CSF$1 \mathrm{R}$ inhibition alters macrophage polarization and blocks glioma progression. Nat Med 2013;19:1264-72.

239.Zhu Y, Knolhoff BL, Meyer MA, et al. CSF1/CSF1R blockade reprograms tumor-infiltrating macrophages and improves response to T-cell checkpoint immunotherapy in pancreatic cancer models. Cancer Res 2014;74:5057-69.

240.Wang Q, Lu Y, Li R, et al. Therapeutic effects of CSF1Rblocking antibodies in multiple myeloma. Leukemia 2018;32:176-83.

241. Ruffell B, Chang-Strachan D, Chan V, et al. Macrophage IL-10 blocks CD8+ T cell-dependent responses to chemotherapy by suppressing IL-12 expression in intratumoral dendritic cells. Cancer Cell 2014;26:623-37.

242.Xu J, Escamilla J, Mok S, et al. CSF1R signaling blockade stanches tumor-infiltrating myeloid cells and improves the efficacy of radiotherapy in prostate cancer. Cancer Res 2013;73:2782-94.

243. Wainberg Z, Piha-Paul S, Luke J, et al. First-in-Human Phase 1 Dose Escalation and Expansion of a Novel Combination, Anti-CSF-1 Receptor (cabiralizumab) Plus Anti-PD-1 (nivolumab). Patients With Advanced Solid Tumors. 32nd SITC Annual Meeting; 2017.

244. Wiehagen KR, Girgis NM, Yamada DH, et al. Combination of CD40 agonism and CSF-1R blockade reconditions tumor-associated macrophages and drives potent antitumor immunity. Cancer Immunol Res 2017;5:1109-21.

245. Ries CH, Hoves S, Cannarile MA, et al. CSF-1/CSF-1R targeting agents in clinical development for cancer therapy. Curr Opin Pharmacol 2015;23:45-51.

246. Magkouta S, Kosti C, Vaitsi P, et al. Targeting of CSF1R abrogates Lewis Lung adenocarcinoma-induced malignant pleural effusion. Eur Respiratory Soc; 2018.

247.Pass HI, Lavilla C, Canino C, et al. Inhibition of the colony-stimulating-factor- 1 receptor affects the resistance of lung cancer cells to cisplatin. Oncotarget 2016;7:56408-21.

248. Eckert F, Schilbach K, Klumpp L, et al. Potential role of CXCR4 targeting in the context of radiotherapy and immunotherapy of cancer. Front Immunol 2018;9:3018.

249. Burger JA, Peled A. CXCR4 antagonists: targeting the microenvironment in leukemia and other cancers. Leukemia 2009;23:43-52.

250. Grande F, Giancotti G, Ioele G, et al. An update on small molecules targeting CXCR4 as starting points for the development of anti-cancer therapeutics. Eur J Med Chem 2017;139:519-30.

251. Taromi S, Kayser G, Catusse J, et al. CXCR4 antagonists suppress small cell lung cancer progression. Oncotarget 2016;7:85185-95.

252. Quail DF, Bowman RL, Akkari L, et al. The tumor microenvironment underlies acquired resistance to CSF$1 \mathrm{R}$ inhibition in gliomas. Science 2016;352:aad3018.

253.Wang HW, Joyce JA. Alternative activation of tumorassociated macrophages by IL-4: priming for protumoral functions. Cell Cycle 2010;9:4824-35.

254.Park-Min KH, Antoniv TT, Ivashkiv LB. Regulation of macrophage phenotype by long-term exposure to IL-10. Immunobiology 2005;210:77-86.

255. Georgoudaki AM, Prokopec KE, Boura VF, et al. Reprogramming tumor-associated macrophages by antibody targeting inhibits cancer progression and metastasis. Cell Rep 2016;15:2000-11.

256. Myers KV, Amend SR, Pienta KJ. Targeting Tyro3, Axl and MerTK (TAM receptors): implications for macrophages in the tumor microenvironment. Mol Cancer 2019;18:94.

257.Linger RM, Cohen RA, Cummings CT, et al. Mer or Axl receptor tyrosine kinase inhibition promotes apoptosis, blocks growth and enhances chemosensitivity of human non-small cell lung cancer. Oncogene 2013;32:3420-31.

258.Zhang G, Wang M, Zhao H, et al. Function of Axl receptor tyrosine kinase in non-small cell lung cancer. Oncol Lett 2018;15:2726-34.

259. Xie S, Li Y, Li X, et al. Mer receptor tyrosine kinase is frequently overexpressed in human non-small cell lung cancer, confirming resistance to erlotinib. Oncotarget 2015;6:9206-19.

260. Cummings CT, Zhang W, Davies KD, et al. Small Molecule Inhibition of MERTK Is Efficacious in NonSmall Cell Lung Cancer Models Independent of Driver Oncogene Status. Mol Cancer Ther 2015;14:2014-22. 261.Willingham SB, Volkmer JP, Gentles AJ, et al. The CD47- 
signal regulatory protein alpha (SIRPa) interaction is a therapeutic target for human solid tumors. Proc Natl Acad Sci U S A2012;109:6662-7.

262.Zhang X, Wang Y, Fan J, et al. Blocking CD47 efficiently potentiated therapeutic effects of anti-angiogenic therapy in non-small cell lung cancer. J Immunother Cancer 2019;7:346.

263. Zhang X, Fan J, Wang S, et al. Targeting CD47 and autophagy elicited enhanced antitumor effects in non-small cell lung cancer. Cancer Immunol Res 2017;5:363-75.

264. Richards DM, Sefrin JP, Gieffers C, et al. Concepts for agonistic targeting of CD40 in immuno-oncology. Hum Vaccin Immunother 2020;16:377-87.

265.Imaizumi K, Kawabe T, Ichiyama S, et al. Enhancement of tumoricidal activity of alveolar macrophages via CD40CD40 ligand interaction. Am J Physiol 1999;277:L49-L57.

266.Zheng X, Sarode P, Weigert A, et al. Re-Education Of Tumor-Associated Macrophages By Modulating Histone Deacetylases In Lung Cancer. Am J Respir Crit Care Med 2017:A6773-A.

267.Guerriero JL, Sotayo A, Ponichtera HE, et al. Class IIa HDAC inhibition reduces breast tumours and metastases through anti-tumour macrophages. Nature 2017;543:428-32.

268. Foubert P, Kaneda MM, Varner JA. PI3K $\gamma$ activates integrin $\alpha 4$ and promotes immune suppressive myeloid cell polarization during tumor progression. Cancer Immunol Res 2017;5:957-68.

269. Kaneda MM, Cappello P, Nguyen AV, et al. Macrophage $\mathrm{PI} 3 \mathrm{~K} \gamma$ drives pancreatic ductal adenocarcinoma progression. Cancer Discov 2016;6:870-85.

270. Kaneda MM, Messer KS, Ralainirina N, et al. PI3K $\gamma$ is a molecular switch that controls immune suppression. Nature 2016;539:437-42.

271.Sun X, Zhu D, Cai Y. Macrophages mediated biomimetic drug delivery systems. J Nanomed 2018;1:1003.

272.Papa S, Ferrari R, De Paola M, et al. Polymeric nanoparticle system to target activated microglia/ macrophages in spinal cord injury. J Control Release 2014;174:15-26.

273.Pang L, Zhu Y, Qin J, et al. Primary M1 macrophages as multifunctional carrier combined with PLGA nanoparticle delivering anticancer drug for efficient glioma therapy. Drug Deliv 2018;25:1922-31.

274. Choi MR, Stanton-Maxey KJ, Stanley JK, et al. A cellular Trojan Horse for delivery of therapeutic nanoparticles into tumors. Nano Lett 2007;7:3759-65.

275. Wang H, Shrestha TB, Basel MT, et al. Magnetic-Fe/
Fe3O4-nanoparticle-bound SN38 as carboxylesterasecleavable prodrug for the delivery to tumors within monocytes/macrophages. Beilstein J Nanotechnol 2012;3:444-55.

276. Guo L, Zhang Y, Wei R, et al. Lipopolysaccharideanchored macrophages hijack tumor microtube networks for selective drug transport and augmentation of antitumor effects in orthotopic lung cancer. Theranostics 2019;9:6936-48.

277. Yousefpour P, Chilkoti A. Co-opting biology to deliver drugs. Biotechnol Bioeng 2014;111:1699-716.

278. Hao Q, Vadgama JV, Wang P. CCL2/CCR2 signaling in cancer pathogenesis. Cell Commun Signal 2020;18:82.

279. Laparidou M, Schlickenrieder A, Thoma T, et al. Blocking of the CXCR4-CXCL12 Interaction Inhibits the Migration of Chicken B Cells Into the Bursa of Fabricius. Front Immunol 2020;10:3057.

280. Yang Q, Guo N, Zhou Y, et al. The role of tumorassociated macrophages (TAMs) in tumor progression and relevant advance in targeted therapy. Acta Pharmaceutica Sinica B 2020;10:2156-70.

281. Chang A. Chemotherapy, chemoresistance and the changing treatment landscape for NSCLC. Lung Cancer 2011;71:3-10

282. Sosa Iglesias V, Giuranno L, Dubois LJ, et al. Drug resistance in non-small cell lung cancer: a potential for NOTCH targeting? Front Oncol 2018;8:267.

283. Correia AL, Bissell MJ. The tumor microenvironment is a dominant force in multidrug resistance. Drug Resist Updat 2012;15:39-49.

284. Castells M, Thibault B, Delord JP, et al. Implication of tumor microenvironment in chemoresistance: tumorassociated stromal cells protect tumor cells from cell death. Int J Mol Sci 2012;13:9545-71.

285. Meads MB, Gatenby RA, Dalton WS. Environmentmediated drug resistance: a major contributor to minimal residual disease. Nat Rev Cancer2009;9:665-74.

286. Paulus P, Stanley ER, Schäfer R, et al. Colonystimulating factor-1 antibody reverses chemoresistance in human MCF-7 breast cancer xenografts. Cancer Res 2006;66:4349-56.

287. Shree T, Olson OC, Elie BT, et al. Macrophages and cathepsin proteases blunt chemotherapeutic response in breast cancer. Genes \& development 2011;25:2465-79.

288. Yin Y, Yao S, Hu Y, et al. The immunemicroenvironment confers chemoresistance of colorectal cancer through macrophage-derived IL6. Clin Cancer Res 2017;23:7375-87. 
289. Weizman N, Krelin Y, Shabtay-Orbach A, et al.

Macrophages mediate gemcitabine resistance of pancreatic adenocarcinoma by upregulating cytidine deaminase.

Oncogene 2014;33:3812-9.

290. Raggi C, Mousa H, Correnti M, et al. Cancer stem cells and tumor-associated macrophages: a roadmap for multitargeting strategies. Oncogene 2016;35:671-82.

291.Jinushi M, Baghdadi M, Chiba S, et al. Regulation of cancer stem cell activities by tumor-associated macrophages. Am J Cancer Res 2012;2:529-39.

292. Jinushi M, Chiba S, Yoshiyama H, et al. Tumor-associated macrophages regulate tumorigenicity and anticancer drug responses of cancer stem/initiating cells. Proc Natl Acad Sci U S A 2011;108:12425-30.

293. Larionova I, Cherdyntseva N, Liu T, et al. Interaction of tumor-associated macrophages and cancer chemotherapy. Oncoimmunology 2019;8:1596004.

Cite this article as: Sedighzadeh SS, Khoshbin AP, Razi S, Keshavarz-Fathi M, Rezaei N. A narrative review of tumorassociated macrophages in lung cancer: regulation of macrophage polarization and therapeutic implications. Transl Lung Cancer Res 2021;10(4):1889-1916. doi: 10.21037/tlcr-20-1241

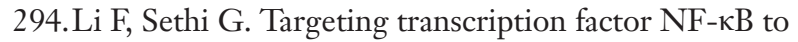
overcome chemoresistance and radioresistance in cancer therapy. Biochim Biophys Acta 2010;1805:167-80.

295. Baer M, Dillner A, Schwartz RC, et al. Tumor necrosis factor alpha transcription in macrophages is attenuated by -an autocrine factor that preferentially induces NF- $\mathrm{NB}$ p50. Mol Cell Biol 1998;18:5678-89.

296. Smith MP, Sanchez-Laorden B, O'Brien K, et al. The immune microenvironment confers resistance to MAPK pathway inhibitors through macrophage-derived TNFa. Cancer Discov 2014;4:1214-29.

297.Fu XT, Song K, Zhou J, et al. Tumor-associated macrophages modulate resistance to oxaliplatin via inducing autophagy in hepatocellular carcinoma. Cancer Cell Int 2019;19:71. 